\title{
The Phenomenology of Leadership
}

\author{
Wiley W. Souba \\ Geisel School of Medicine, Dartmouth College, Hanover, USA \\ Email: Chip.Souba@Dartmouth.edu
}

Received 15 October 2014; revised 16 November 2014; accepted 30 November 2014

Copyright (C) 2014 by author and Scientific Research Publishing Inc.

This work is licensed under the Creative Commons Attribution International License (CC BY). http://creativecommons.org/licenses/by/4.0/

(c) (i) Open Access

\section{Abstract}

Teaching people about leadership is different from creating leaders. Teaching leadership uses a third-person approach to impart someone else's knowledge, which grants learners limited direct access to the being and actions of effective leaders. In contrast, creating leaders entails a firstperson phenomenological methodology, which provides direct access to what it means to be a leader and what it means to exercise good leadership in real time, with real results. The distinctiveness of the first-person "as-lived/lived-through" approach lies in its capacity to disclose the hidden contexts that shape the ways of being, thinking, and acting that are the source of the leader's performance. When these contexts become unveiled, it allows for the creation of new contexts that give leaders more space and more degrees of freedom to lead effectively as their natural selfexpression. A phenomenological inquiry into leadership does not study the attributes of leaders, but rather the fundamental structures of human "being" that make it possible to be a leader in the first place. Because the phenomenological "facts" of lived experience reside in language, creating for oneself what it is to be a leader entails mastering a special language (that includes terms like intentionality; thrownness; being-in-the-world; clearing-for-action; absorbed coping; hermeneutic; and, break-down) from which leaders can orient their being, thinking, and actions. Learning to be a leader is not first and foremost about the acquisition of knowledge or certain personal attributes. Rather, only when leadership becomes an as-lived/lived-through experience does it grant access to its actual nature and essence.

\section{Keywords}

First-Person, As-Lived, Existentials, Ontology, Direct Access, Language

\section{Introduction}

As the magnitude and complexity of global issues, problems, and challenges increase, the need for better leadership from more people is more critical than ever. Yet, in spite of this urgency, we continue to fall short in 
developing $21^{\text {st }}$ century leaders. We ask, often apathetically, why we have such a leadership vacuum but our search for answers seems to invariably come up empty handed. In his magnum opus, On Leadership, John Gardner observes that when we ask a question countless times and arrive at no answer, we may be asking the wrong question or have misconceived the terms of the query (Gardner, 1990). Rather than wondering why the world is lacking in good leadership, we might begin by asking what it means to be a leader.

Leadership education today is largely a third-person undertaking, which is focused on teaching the learner someone else's knowledge. This third-person approach provides limited direct access to the being and actions of effective leaders. It is unrealistic to expect learners to be able to master something as complex and convoluted as leadership through disjointed lectures and PowerPoint slide presentations. Moreover, educational approaches that encourage learners to seek first-person as-lived experiences, and reflect on them, are often discounted. This presents the "insurmountable problem of incommensurability between where learners are likely to be in their developmental lived experience and what the educator is likely to require learners to learn" (Iran-Nejad \& Houser, 2013).

The natural sciences deal with a material world of objects, abstracted from human concerns, while the social sciences deal with a world of conscious agents, disconnected from material things (Costall, 1995). Using the time-honored, external third-person perspective of the natural sciences to study leadership is associated with limits on the comprehension of conscious experience and is, therefore, insufficient for understanding the internal first-person subjective point of view (Markic, 2012; Van Gulick, 2014). The natural sciences start from a complex set of presuppositions, beliefs, and frameworks, but these taken-for-granted elements are not questioned by the sciences themselves (Kekes, 1980). The natural sciences, notes Richard Tieszen (Tieszen, 2013), provide us with a kind of objectivity that "leaves behind" our feelings, sensations, and first-person experiences. He writes:

What natural science yields is just the third-person stance on the world. In short, the intention behind it is precisely to...minimize subjectivity and maximize objectivity...The very methods required in order for the natural sciences to be possible are methods that abstract away from subjectivity, consciousness, intentionality, and other features of experience itself...It is not surprising that what is revealed to us is that the nature of human being is quantifiable, formalizable, or computational.

Leadership, however, is not computational, linear, or formulaic. In contrast to the natural sciences, leadership is best studied using a first-person "as-lived" phenomenological inquiry, which uses discourse, deliberation, and reflection to investigate how people experience what they experience and the meaning of that experience, be it a solar eclipse or a leadership challenge. A phenomenological inquiry into leadership does not study the properties and attributes of leaders, but rather the fundamental structures of human "being" that make it possible to be a leader in the first place.

For example, when someone explains to you how to teach, their third-person account gives you no direct access to teaching. You can watch videos and read about teaching, but until you walk into a class and experience for yourself what it's like to be in front of the room on your own, and what it is to engage the learners and have them interact with new ideas and discover together, you cannot master teaching. Likewise, when someone explains leadership to you, their account gives you no direct access to leadership. You may be able to recite various leadership books and articles, but until you experience for yourself firsthand what it is to deal with a complex leadership challenge and to confront your fears and inadequacies in dealing with it, you cannot be a leader or exercise leadership effectively (Table 1).

This paper argues that a phenomenological approach to educating leaders is essential to successfully tackling the world's most vexing problems. In the words of Norbert Wiener, "we have modified our environment so radically that we must now modify ourselves in order to exist in this new environment. We can no longer live in the old one. Progress imposes not only new possibilities for the future but new restrictions" (Wiener, 1988). Because phenomenology employs the first-person "as-lived" perspective, it provides us with direct access to what it means to be a leader and what it is to exercise good leadership. In so doing, our ways of being and acting that limit our freedom to think strategically, innovate, and execute are unconcealed. Once these constraints are unveiled, new possibilities for leading emerge.

\section{Challenging the Prevailing Leadership Paradigm}

Suppose I were to ask you, “What is a university?” You answer, “A university is an institution of higher educa- 
Table 1. Approaches to teaching leadership.

\begin{tabular}{ll}
\hline \multicolumn{1}{c}{ Current Epistemological Approach } & \multicolumn{1}{c}{ Emerging Phenomenological Approach } \\
\hline $\begin{array}{l}\text { Provides learners with } 3^{\text {rd }} \text {-person access to leadership by } \\
\text { teaching someone else's knowledge }\end{array}$ & $\begin{array}{l}\text { Provides learners with direct }\left(1^{\text {st }} \text {-person) access to being a }\right. \\
\text { leader and exercising effective leadership }\end{array}$ \\
$\begin{array}{l}\text { Knowing is the foundation of leadership, anchored in theories } \\
\text { and explanations }\end{array}$ & $\begin{array}{l}\text { Being a leader is the foundation of leadership; knowledge } \\
\text { informs and illuminates }\end{array}$ \\
$\begin{array}{l}\text { Leadership is about a person in charge who wields clout, } \\
\text { controls resources, and has answers }\end{array}$ & $\begin{array}{l}\text { Leadership is an exercise in language that reframes } \\
\text { (recontextualizes) the occurring }\end{array}$ \\
$\begin{array}{l}\text { The barriers to effective leadership are largely external (e.g., a } \\
\text { changing industry environment) }\end{array}$ & $\begin{array}{l}\text { The barriers to effective leadership are largely internal } \\
\text { (intrapersonal) }\end{array}$ \\
\hline
\end{tabular}

tion that confers degrees." Your answer to my question provides me with characteristics and attributes that describe and identify the entity. Suppose I then ask, "What does it mean to be a student enrolled in a university?" In response, you say, "To be a student means to be a learner; a critical thinker; busy studying; inundated; part of a community; prepared for a career, and so on." The first question "What is a university?" is answered in reference to other entities such as professors, students, classrooms, homework, courses, and so on. The second question is answered with regards to what it means to exist as a student in various ways, such as being mentored or being challenged or being studious. The question of the meaning of anything is answered in reference to other meanings.

If we now ask "Which question comes first?" it will, after some thought, become clear that what it means to be a student enrolled in a university is prior to what kind of "thing" a university is, for the meaning determines the entity. If I understand what it means to be a student, I will know what is required to create a university. The inquiry into what it means to be a student in a university is not only different from the question about what kind of thing is a university it is also prior to it, for the meaning ultimately explains the entity (Gelven, 1989).

Suppose I now ask "What is a leader?” You answer, “A leader is a person with a title and authority, with direct reports, with a vision, and so on." Your answer to my question provides me with attributes that describe and identify a leader. Suppose I then ask, "What does it mean to be a leader?" In response, you say, "To be a leader is to be honest; inspiring; forward-thinking; and, committed.” The first question "What is a leader?” is answered in reference to other entities such as a title, people, a strategic plan, and so on. The second question is answered in reference to what it means to exist as a leader in various ways, such as being dedicated or focused or honest. And meaning always precedes entity (Table 2).

What it means to be a leader should be the basis for the way in which we educate and train leaders. If I understand what it means to be a leader, I will know what is required to create a leader. However, when we examine current educational paradigms, we discover that we are not educating or developing leaders in keeping with what it is to be a leader. The focus today is largely on imparting knowledge using third-person educational methods (Iran-Nejad \& Houser, 2013). This must change.

\section{Leadership as a Phenomenon}

Nearly four decades ago, James McGregor Burns (Burns, 1978) wrote that "leadership is one of the most observed and least understood phenomena on earth.” A phenomenon (from Greek phainomenon, meaning "that which appears or is seen”) could be defined as any occurrence, entity, or situation known through the senses rather than by deduction or reasoning. Not infrequently, a phenomenon refers to something that is noticed because it is unusual or new. Leadership is not new or unusual nor is it commonly studied phenomenologically, which may explain our failure to "grasp the essence of leadership that is relevant to the modern age” (Burns, 1978).

Phenomenology is the study of phenomena and the way in which they are experienced from the first-person point of view (Smith, 2013). It is based on the assumption that lived experience is irreducible-that phenomenal data cannot be derived from the third-person perspective (Varela \& Shear, 1999). Phenomenologists ask: What is the nature and essence of the experience of the phenomenon for those who experience it? They are less concerned with the facts of a leadership situation (what actually happened and when, who did what to whom, etc.) and more interested in the first-person as-lived meaning and significance of the experiences of those involved. They maintain that the only way that things (people, incidents, debates) can be known is through the way in 
Table 2. What is (third-person descriptive) vs. what does it mean to be (first-person experiential).

\begin{tabular}{clcl}
\hline $\begin{array}{c}\text { What Is } \\
\text { (An Entity)? }\end{array}$ & \multicolumn{1}{c}{$\begin{array}{c}\text { Third Person Answer } \\
\text { (Descriptive) }\end{array}$} & $\begin{array}{c}\text { What Does Being } \\
\text { (An Entity) Mean? }\end{array}$ & $\begin{array}{c}\text { First Person Answer } \\
\text { (As-Lived Experience) }\end{array}$ \\
\hline $\begin{array}{c}\text { What is a } \\
\text { human being? }\end{array}$ & $\begin{array}{l}\text { A member of Homo sapiens, that species } \\
\text { differentiated by its speech, large frontal } \\
\text { lobes, upright posture, capacity to make } \\
\text { and use complex tools, opposable thumb, } \\
\text { and abstract reasoning ability. }\end{array}$ & $\begin{array}{c}\text { What does it mean } \\
\text { to be human? }\end{array}$ & $\begin{array}{l}\text { Being human means: } \\
\text { being-in-the-world-(thrown); } \\
\text { being-in-language; being-with-others; } \\
\text { being-as-care; being-a-temporal-unfolding. }\end{array}$ \\
$\begin{array}{c}\text { What is a } \\
\text { leader? }\end{array}$ & $\begin{array}{l}\text { A person in charge (of a group, } \\
\text { organization, corporation, team, or unit) } \\
\text { who wields clout, has answers, allocates } \\
\text { resources, and directs followers. }\end{array}$ & $\begin{array}{l}\text { What does it mean } \\
\text { to be a leader? }\end{array}$ & $\begin{array}{l}\text { Being a leader means using language to } \\
\text { reframe people's challenges such that more } \\
\text { effective ways of being and acting are the } \\
\text { outcome. }\end{array}$ \\
\hline
\end{tabular}

which we (as individual subjects) experience them (Douglas \& Wykowski, 2010). Phenomenology attempts to describe accurately and fully the essential features of our active, engaged everyday lived experiences: observing an argument; hearing a complaint; watching a lecture. This requires bracketing those taken-for-granted beliefs and hidden worldviews so as to overcome "the strait-jacket of encrusted traditions" (Moran, 2000). Most phenomenologists agree, however, that description always involves some degree of interpretation such that the observer cannot fully detach himself from the world (and so cannot have an unbiased viewpoint). Von Ward describes the cunning nature of our worldviews:

When people speak and act on worldviews so deeply inculcated since birth, they are unconscious of the fact they are simply beliefs. At a conscious level the beliefs are taken as real as one's hand. These beliefs-regardless of the lack of objective, external evidence-form a gyroscope-type mechanism that insures the individual's behavior remains consistent with his or her subconscious sense of self (Von Ward, 2012).

Thus, subjectivity is always involved in the process of constituting objectivity-we invariably bring our beliefs and prejudices to our interpretation of reality and these prejudgments include our historical-cultural backgrounds as well as our individual experiences (Figure 1). In McKenna's words, phenomenology is concerned with "whatever of the world I am conscious of is there for me through my being conscious of it” (McKenna, 1982). Kockelmans notes that "at the very moment the [leader] begins to reflect he has already engaged himself in the world, society, history, language...The phenomena, the things themselves, must be accepted by the [leader] the way they really are, but this can be done only by interpreting them from a conception of world which is already there before the [leader] can begin to reflect” (Kockelmans, 1987). In other words, the study of the objects of consciousness always involves some apriori understanding of that subject. While neuroscientists and cognitive psychologists are interested in how consciousness is constituted, phenomenologists are more interested in how "things" (people, situations, events) reveal themselves to us in our lived experience.

We each have our own perspective of reality that we can only interpret through our senses and unique experiences. Phenomenology as a method of inquiry is valuable because we can never know something objectively, as it actually is. To do that, we would have to become that something. The observing is not the observed. I can describe you, categorize you, and compare you, but my observations and characterizations are not you. In Liang's words, "I see you, and you see me. I experience you, and you experience me. I see your behavior. You see my behavior. But I do not and never have and never will see your experience of me, just as you cannot 'see' my experience of you. My experience of you is not 'inside' me. It is simply you, as I experience you. And I do not experience you as inside me. Similarly, I take it that you do not experience me as inside you” (Laing, 1967). Thus, there are only my observations and they will be different than those of others. Burch explains further:

The locus of phenomenological reflection, its beginning and end, is the intelligibility of lived experience...At its origin, lived experience is a self-constituting (and hence dialectical) process...Any experience can be mine only insofar as I constitute it as mine, bringing it meaningfully to be and making it my own, integrating and reintegrating the constituted meaning into the course of my life...A lived experience is always essentially one's own direct experience, a moment in the suite of occurrences that make up a personal life (Burch, 1990).

For example, even though most of have two kidneys, we have no direct access to what it means to be a kidney. 


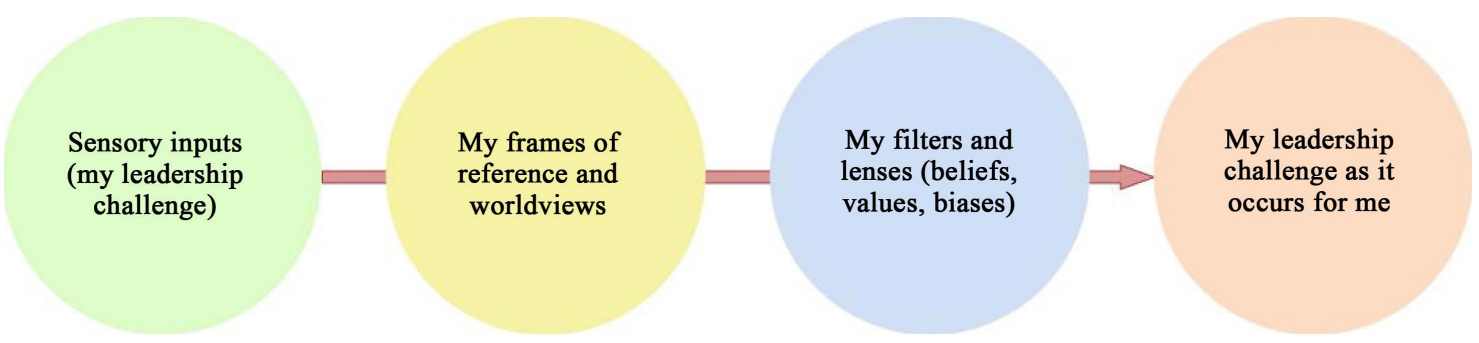

Figure 1. Our brain-generated reality. The bulk of our sensory information (much of which we are not consciously aware) is immediately discarded as irrelevant. The brain fits the remaining inputs into our existing mental models. Phenomenological research attempts to understand the nature and essence of leadership as a phenomenon. It focuses on the meanings of our leadership experiences and what it means to be human in leadership situations as they occur in the course of daily life. A phenomenological inquiry into leadership will not look at the properties and attributes of leaders, but rather at the structures which make it possible to be a leader in the first place.

We can only measure (third-person) what a kidney does and then describe its properties and functions (filtering blood and making urine, for example). But these properties give us no direct (first-person) access to what it means to be a kidney. Similarly, you may memorize the attributes of good leaders but they provide you no direct access to what it means to be a leader. You do, however, have direct access to what it is to be human. It's the only entity to which you have direct access (Souba, 2014). And through accessing what it is to be human-and who you really are-you can access what it is to be a leader. Yet, while the "as-lived first-person perspective" is essential to phenomenological inquiry, there are two additional elements that must be recognized. Anton explains:

[R]esearching "lived-through experience" [and] adhering to a "first-person perspective” are not to be denied, but the much more vital aim is careful elucidation of invariant or essential features of experiences or phenomena...The most fundamental and defining insight within phenomenology regards the notion of "intentionality", that "all consciousness is consciousness of something"...The second...concerns the distinction between "reflective" and "pre-reflective" modes of intentionality. Said simply, acts of consciousness and their correlated objects vary significantly in their degree of explicitness or transparency...[S]ometimes we seem mindlessly installed in a host of background practices;... "transparent, absorbed, lost in the flow". At other times...we explicitly and consciously posit our intentional acts as an addition to whatever they reveal, disclose and/or are about (Anton, 2014).

The phenomena that comprise the intentionality of the leader's consciousness might be a strategic plan, a budget crisis, a dysfunctional team, or an organizational culture. The method of phenomenology gives us direct access to the way in which leader and leadership occur for us in dealing with these challenges, often by jarring us loose from the engrained, hidden frames of reference that we are so attached to and yet so unaware of. In contrast to other qualitative research methods, phenomenology emphasizes the subjective point of view by encouraging individuals to reflect on the essence of their experiences. In examining how a particular leadership challenge occurs for people, contextual differences can be unpacked and hidden barriers that limit our leadership effectiveness can be uncovered.

Phenomenology is apt for studying leadership because our primary encounter with the world is not theoretical; it is not the experience of some detached spectator gazing out at a world bereft of meaning or importance (Critchley, 2009a). Rather, as life is lived, our basic relationship to the world is practical and hands-on; we lead moment-to-moment, situation-to-situation in the way we experience leadership "as-lived", that is, from a first person point of view. We encounter people as people, not as a collection of organs inside a skin bag just as we encounter kitchen cabinets as objects to store dishes in, not as pieces of wood held together by glue and screws.

In studying the taken for granted beliefs and views that human beings "carry around in their heads", phenomenologists strive to "unconceal" the inherent structures that constitute and shape human experiences. Possible meanings are unpacked by challenging existing taken-for-granted frames of reference, employing polarities and reversals, and approaching the phenomenon from divergent perspectives, different positions, roles, or functions - the aim is to discover the underlying and precipitating factors accounting the experiences (Moustakas, 1994).

However, even though we observe the same conversation or set of circumstances, no two people ever have the 
same lived experience. Once an event or situation is perceived and interpreted, the task of making meaning with language remains. Without the ability to convert an event or an experience into an object (by speaking), we could not make meaning of things. "Language creates consciousness in human beings", notes Carruthers; "take away language and you take away much of what it means to be human” (Carruthers, 1996), said otherwise by Bineham, our medium of understanding the world.

Is fundamentally linguistic in nature. [First], one cannot speak of a medium without consideration of how it is constructed and sustained in language. In a crucial sense language is the medium. Second, the medium embodies history. To live within a medium means to live within a particular historical tradition and to be guided by the mores and assumptions of that tradition (Bineham, 1995).

Our world is never wordless. Our experiences become an object of reflection by being named with words. For human beings to be-in-the-world at all is to be in a linguistically constructed world. Palmer (Palmer, 1969) circumscribes the issue with a question: “And what is the medium in and through which ontological disclosure can take place...? What is the medium that is inseparable from experience itself, inseparable from being? The answer must be: language.” Experience, however, is always more obscure and elaborate than any description can fully capture. Van Manen’s (Van Manen, 2014) somewhat lengthy quote is helpful:

What we try to do in phenomenological research is to evoke understandings through pathic mediations of language...that transcend the common cognitive function of language. If we want to come to an understanding of the unique meaning and significance of something we need to reflect on it by practicing a thoughtful attentiveness...How do we capture and interpret the possible meanings of such experiences? The things we are trying to describe or interpret are not really things at all-our actual experiences are literally nothings, nothings. And yet, we seem to create something when we use language in phenomenological inquiry.

\section{Being vs. A Being}

Prior to the 1900s, ontology was largely concerned with entities (“things”)—e.g., human beings- and their properties and classifications. However, defining human beings in terms of characteristics and properties overlooks a more basic and primary question: What does it mean to exist at all (in the first place)? To ask what it means "to be” is to engage in the most fundamental kind of questioning possible (Gelven, 1989). Because the word "being” is generally understood as an abstract noun (a "thing”), the practice that has been accepted by most translators is to capitalize the letter $\mathrm{B}$ when referring to being, the verb, so that when we use the term "Being" the reader should keep in mind that what it really means is “to be” (Gelven, 1989).

Heidegger was interested in that kind of "analysis by which the meaning of [the] various ways in which we exist can be translated from the vague language of everyday existence into the understandable and explicit language of ontology without destroying the way in which these meanings manifest themselves to us in our everyday lives” (Gelven, 1989). He employed the phenomenological method to describe the nature of human being as Dasein, a German term which literally means "there-being” or Being-already-engaged-in-world. Dasein is not to be construed as a concrete entity that exists in a circumscribed place. Rather Dasein as "being-there” refers to a space of intelligibility on the basis of which things emerge-into-presence as the kinds of things they are (Aho, 2009). The term Dasein (as opposed to consciousness or subjectivity) is used to convey that we are already always in and involved with the world, existing against a contextual background upon which all ways of being, thinking, and acting are contingent. In other words, we are inescapably immersed in and wrapped up in the world, always in context, never able to be separated from our "thrown situatedness." Heidegger argued that human beings cannot entirely bracket the world of their experience; to "be" is to be engaged in the world of experience-human beings know themselves only through experience and as embedded in a world.

Most people understand human beings in terms of what they are and that they are (e.g. "I am Irish" and "I live in Ireland"). Unlike previous scholars who queried the properties and characteristics of the human person, Dasein is that entity for which the meaning of being is a concern for it; in and through its day to day ways of being, its Being is revealed to itself. Sallis (Sallis, 1995) asks a logical and valid question: "But why Dasein and not simply man? Certainly there could be no beings with the character of Dasein who would not also be men, nor conversely." His answer is illuminating:

The point is that the designation Dasein is open to a radically different way of the matizing the being so 
designated, in contrast to a designation such as man, in which a virtually uncontrollable complex of presupposition is operative, most notably, those connected with the determination of man as "rational animal”...To designate this being as Dasein is...to place it from the outset in relation to Being; to designate it thus is to prepare an interrogation of it as the Da of Sein, as the place of questioning about Being.

Dasein, then, is a new term for a human being that is already always there, embedded in the world. Dasein is uniquely human in that it is conscious of its own existence, has capacities for language and communication, engages in self-talk, and is endowed with complex analytical abilities. The world and Dasein itself are only perceived and understandable by way of Dasein's own awareness of its Being. In Sartre's words, "What do we mean by saying that existence precedes essence? We mean that man first of all exists, encounters himself, surges up in the world- and defines himself afterwards" (Sartre, 1946).

Each Dasein must understand itself within some culture that already has a perspective on specific possible ways to be human-on what it means to be (Dreyfus, 1991). And because Dasein as "already-always-being-there" is prior to its own emotions, thoughts, and attitudes, its own structure of Being is essentially veiled. Unveiling the structures constitutive of Dasein is the task phenomenologists take on.

We human beings understand ourselves by projecting ourselves forward into some way of life, through possibilities for being. For example, a minister understands herself as a minister by projecting herself forward into a minister's way of life. Such projection, moreover, is not a cognitive or intellectual achievement, nor even an imaginative one, but rather a concrete form of conduct (Dreyfus \& Wrathall, 2005). Heidegger characterizes it as "pressing ahead" into the activity of being what one understands oneself to be. We project forth into the possibilities we pursue because they matter to us as they do. I press ahead into being a physician because it is rewarding. If those possibilities did not matter to me as they do, I would pursue others.

Ideas on the primacy of Being have made their way into linguistics, communication theory, theology, and the cognitive sciences, but their relevance to leadership have been largely unrecognized. A natural extension, especially given the global imperative for more effective leadership, would be to ask: "What does it mean to be a leader?" and "What does it mean to exercise effective leadership?"

\section{Structures Constitutive of Human Being}

A central premise of this paper is that what it is to be a leader is inextricably linked to what it is to be human. Superb leadership (the kind needed to transform the world) begins with understanding the being aspect of human being. We cannot effectively lead "out-here" unless we have a strong internal leadership foundation. Said otherwise, leading yourself is a prerequisite for leading others. Individual transformation must parallel (or precede) organizational transformation. As the pace of external change accelerates, the "you" that shows up to work each day won't cut it. A different you will be called for. A phenomenological inquiry is concerned with the existential structures which make it possible to be a leader in the first place. No menu of "properties" can grant us first person access to leadership.

The essence of the entity that each of us is lies in its existence; its ontological characteristics, accordingly, are structures constitutive of human "being" (Dreyfus \& Wrathall, 2005). Those structures that are unique to Dasein are called existentials. Typically, when we analyze any other entity, we do so in terms of properties, characteristics or categories. The structure of human being, however, must be delineated existentially. Existentials are characteristics (structures) of human "Being" that are revealed by the analysis of its existence (Figure 2). Existentials always concern our living in the world and our involvement with entities within the world. These structures of human "being" are already always there no matter what situation you and I are dealing with and no matter what our way of being and acting in dealing with it. Accordingly, anyone can lead.

\subsection{Being-in-the-World-(Thrown)}

The primordial structure of existence is "being-in-the-world" (Heidegger, 1996). A metonym for Dasein, "being-in-the-world" signifies the unified phenomenon in terms of which Dasein understands its world, who it is (particularly in its day to day routine activities), and its ways of being in the world (Dahlstrom, 2014). Our very existence necessarily presupposes a world that we are inescapably in. We are thrown into a body and into the world; we are always dealing with something (a situation, a person, a problem) by being some way.

Dasein's being-in-the-world is different than that of an object, such as the scissors being in the drawer or the 


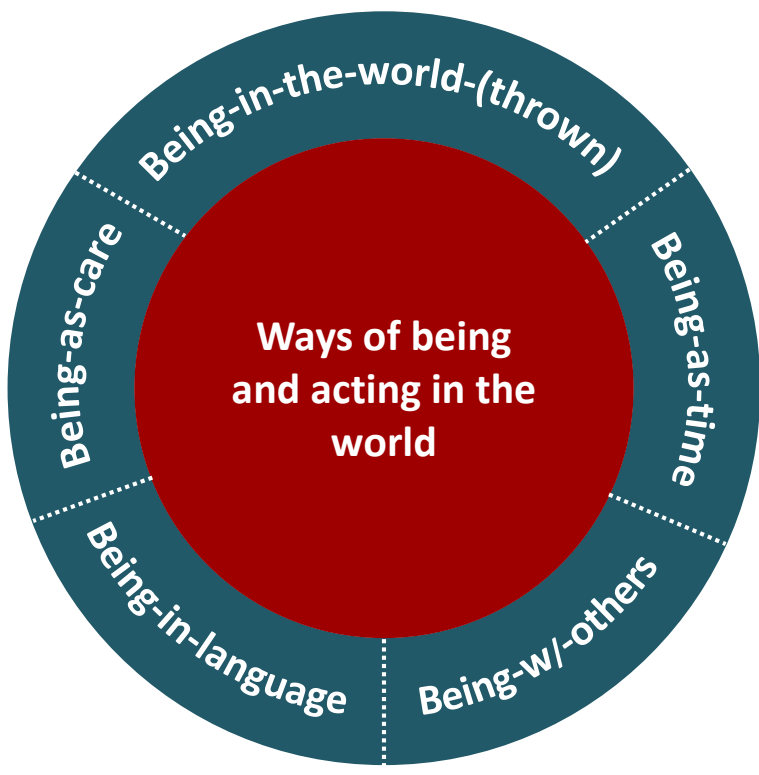

Figure 2. Structures constitutive of human "being”. Being-inthe-world-(thrown), Being-as-time, Being-with-others, Beingin-language, and Being-as-care are fundamental modes of existence that are constitutive of human "being." As such, they are already always there. Overlaid on these essential structures (characteristics) are the leader's moment-to-moment, situation-to-situation ways of being and acting, which are a correlate of the way in which the particular situation the leader is dealing with occurs for him/her.

milk being in the refrigerator. The Being-in dimension of Being-in-the-world is not some coordinate in spacetime that can be defined by the mathematics of general relativity. Rather "in" denotes an existential element which conveys involvement, as in being in a wedding, being in court, or being in the hospital. Being-in-theworld always entails dealing with a particular set of circumstances, from a certain point of view, with a certain way of being. Said otherwise, "Self and world belong together...[They] are not two beings, like subject and object, or like I and thou, but self and world are the basic determination of Dasein itself in the unity of the structure of being-in-the-world" (Heidegger, 1982).

Being and the world cannot be understood separately, since the world is already there "pregiven", and being exists as hurled into it. In other words, humans can only be as being-in-the-world; "the notion of existential identity and that of world are completely wedded. To be at all is to be worldly” (Steiner, 1978). Geniusas elaborates:

[That the natural world] is pregiven does not simply mean that it is the ground upon which, and the context within which, objects appear. Its pregivenness also stamped objects as worldly...The pregivenness of the world is taken by the natural consciousness to mean the world's anteriority in regard to the accomplishments of consciousness (Geniusas, 2012).

Much of our being-in-the-world does not require focused engagement in the sense that most of our everyday activities (getting dressed, walking the dog, taking out the trash, television channel-surfing) proceed in a more or less non-reflective, non-intentional way, unless there is a disruption in these routine practices (e.g., the television remote control quits working). Dreyfus contrasts between "two distinct kinds of intentional behavior: deliberative, planned action, and spontaneous, transparent coping” (Dreyfus, 2002). Transparent absorbed coping is prominent at "high levels of expertise, whether in sport, chess, nursing, or driving, [such that] action management and decision-making do not even appear as problems for the expert practitioner [master]" (Sutton et al., 2011). We encounter ourselves primarily in the actual acts that arise out of our intentions, rather than by directly looking at the intentions that might or might not give rise to acts (Okrent, 1999). 
In probing the Dasein Analytic to uncover the fundamental structures of human existence, Heidegger coins the provocative term "thrownness" to characterize our inevitable submission to existence itself. We are "thrown" into the world- and into whatever situation or set of circumstances we happen to be dealing with-often with no say on our part. Moreover, this world that we are always already thrown into is one that often seems indifferent to our concerns. Dasein is thrown into its "there" (Da) but Dasein does not sit idle because it always finds itself "thrown" into a world that matters to it in some way or another.

In being thrown, Dasein is propelled into a way of being that Heidegger calls "projecting”. Dasein projects itself onto its possibilities (Heidegger, 1996). Projecting differs from Dasein's thrownness in that it is performed by Dasein itself. Dasein cannot project whatever it likes; it is limited by its possibilities, some of which are handed down to it by its lineages, for confronting whatever situation it is thrown into. Thus, in some sense, Dasein is foundationless because it is always already thrown and, in dealing with its thrownness, Dasein can only ever choose one "course" and must tolerate not having chosen others and not being able to. Wheeler offers this helpful explanation:

Dasein confronts every concrete situation in which it finds itself (into which it has been thrown) as a range of possibilities for acting (onto which it may project itself). Insofar as some of these possibilities are actualized, others will not be, meaning that there is a sense in which not-Being (a set of unactualized possibilities of Being) is a structural component of Dasein's Being. Out of this dynamic interplay, Dasein emerges as a delicate balance of determination (thrownness) and freedom (projection) (Wheeler, 2013).

By projecting itself upon possibilities-as potential ways of being and acting for dealing (coping) with whatever it is thrown into-Dasein understands itself (its existence). In other words, "Dasein has, as Dasein, always already projected itself; as long as it is, it is projecting. As long as it is, Dasein always has understood itself and always will understand itself from possibilities” (Heidegger, 1962). In being those possibilities, Dasein’s being reveals a care and concern by which it understands itself.

We each have some particular way in which we understand who we are. Our actions (or inactions) are consistent with the ways in which we identify ourselves. A conception of your practical identity is "a description under which you value yourself, a description under which you find your life to be worth living and your actions to be worth undertaking” (Korsgaard, 1996). As Steiner (Steiner, 2002) says:

Our fundamental nature [is] to be practically rather than theoretically open to the world. To be practically open means to do things with the world, to be active, to be engaged in human pursuits, to be hands on, to get our hands dirty, rather than "living in our heads"... Interpretation does not happen in our heads. It happens in the world. Those phenomenal links that are being followed are not in our heads. They are all around us and can be understood if we are open to them.

At the most basic level of being-in-the-world, there is always a mood, a mood that "assails us" in our "absorbed coping" in our daily activities (Dreyfus, 1991). Moods contribute to our moment-to-moment, situation-to-situation "way of being," the ground for our thinking, doing, and acting. In Flatley's (Flatley, 2008) words, "One is never not-attuned; one is always in one mood or another. The world never presents itself to us as some kind of value-less set of facts or perceptions-things always appear to us as mattering or not mattering in some way." We confront the myriad of situations we find ourselves thrown into via a range of "projected" possibilities for being and acting. In other words, you and I are always dealing with something - a person, a problem, a setback - and we're always being some way in dealing with it. Our thrownness shows up for us, in part, as being in a mood that "implies adisclosive submission to the world, out of which we can encounter something" (Blattner, 2006a). Mood "comes neither from 'outside' nor from 'inside', but arises out of Being-in-the-world, as a way of such being” (Heidegger, 1996). A mood is in us as much we are in a mood.

\subsection{Being-with-0thers}

Dasein's everyday world is a shared world; "Dasein establishes and maintains its relation to itself in and through its relation with Others" (Mulhall, 1996). In Heidegger's words, "the world of Dasein is a with-world...Being-in is Being-with Others" (Heidegger, 1996). Said otherwise, just as Dasein is never without a world, it is never without others. Even if one lives as an anchorite, Dasein is always being-with since other people are never inconsequential. 
Being-with is an existential characteristic of Dasein even when...no Other is present...Even Dasein's Being-alone is being-with in the world...Being missing and "Being away" are modes of Dasein-with, and are possible only because Dasein as Being-with lets the Dasein of Others be encountered in the world (Calarco \& Atterton, 2003).

Thus, Being-with and Being-in-the-world are inextricably linked. Being-with is, says Heidegger, “equiprimordial” with being-in-the-world. Human "being” (existence) is essentially being-in-the-world and it is equally essentially being-with (Schatzki, 2005). While Being-with affords us a capacity for understanding others, Heidegger characterizes Dasein's everyday being-with-one-another as "the they." He uses this concept to explain our inauthentic ways of being, in which what we do is only because "that is what one does" or "what everyone else does" or "that's just the way we do things." He says that when "the they" stipulates what and how one "sees" and becomes responsible for every judgment and decision as its own, it takes the responsibility of Dasein away from it...The they always "did it," and yet it can be said that "no one” did it (Heidegger, 1996). He writes:

As everyday being-with-one-another, Dasein stands in subservience to the others. It itself is not; the others have taken its being away from it. The everyday possibilities of being of Dasein are at the disposal of the whims of the others... “The others,” whom one designates as such in order to cover over one's own essential belonging to them, are those who are there initially and for the most part in everyday being-withone-another. The who is not this one and not that one, not oneself and not some and not the sum of them all.

The "who" is the neuter, the they.

Heidegger contrasts Dasein’s everyday inauthentic “they-self” from the authentic self. Authentic being one’s self is not about disengaging from "the they"; rather it is about a reframing. Guignon points out that "since our own life stories are inseparable from the wider text of a shared we-world, authenticity can be nothing other than a fuller and richer form of participation in the public context” (Guignon, 1993). Existence, authentic or not, is an ongoing projection of possibilities, in and through which Dasein discloses its being to itself and others.

\subsection{Being-as-Care}

Dasein's most fundamental way of being is to be concerned for its being (its being is an issue for it), and this basic kind of being (existence) is understood as care (Dreyfus, 1991). Care (concern) is the result of Dasein's relationship with things in the world. Heidegger says that we "comport" ourselves to others in the manner of "caring for". We reveal our care by projecting ourselves onto our thrown possibilities-in so doing, we acquire an understanding of who we are. "We care for other beings not for any extrinsic good," says Borrie, "but rather as a sense of identification or oneness with all things. Our relationship with the world is therefore concernful and participatory rather than perceptual and objectified” (Borrie, 1995). A potter, for example, practices the skills of wedging, kneading, and shaping clay in order to create earthenware, stoneware and porcelain, but ultimately for the sake of being an artist. What ultimately motivates all learning and all action is that only through action does one acquire an identity, and having an identity, a way of being and acting, is what human being is all about (Dreyfus, 1991).

Dasein's being reveals a care and concern by which it understands, manifests, and transcends itself. Care is manifested as "having to do with something, producing something, attending to something...” (Heidegger, 1962). This is in contrast with entities that lack the capacity for self-reflection. A coffee table, for example, does not have the capacity to choose where or how it wants to be. Dasein's Being is always looking out towards the world and, therefore, is essentially manifested in care and concern. In making the Being of Dasein visible as care, care itself must be taken as an ontological structural concept. In this sense, care has nothing to do with its everyday burdens and afflictions that are just part of life.

This concept of care opens up Heidegger's distinction between the authentic self and its inauthentic counterpart. The authentic self is the self that is mine (living a life that is owned by me, not others), whereas the inauthentic self is the self lost to the "they". To live authentically means to be, regardless of the situation we are thrown into, responsible for what is now and for creating our future. Inauthentic ways of being and acting include succumbing to-falling into- the "rat race" of looking good, controlling and manipulating others for selfish ends, gossiping, and busyness (Agosta, 2010). Authenticity is not about being isolated from others, but rather about finding a different way of relating to others such that one is not lost to the they-self. Lebeau and McClain (Lebeau \& McClain, 2006) explain: 
[Our] "thrownness" is not something over which we have control or which we have consciously chosen... Thus, we embark upon our life journey from a position of absolute innocence and we must assume absolute responsibility for where we find ourselves if we are to live authentically. We could not choose how we were "thrown" but what we can choose, and this is the crucial responsibility of being human, is how to be with how we were thrown.

Thus, we are thrown into our existence as a realm of possibilities, and we understand whatever we confront through some way of being and acting. Because our way of being-in-the-world is as being-as-care, we are not "stuck" with our thrownness. We can "throw off" our thrownness by projecting ourselves onto our possibilities by being and acting in a particular way in a particular situation. The experience of this "projection" is what Heidegger calls freedom-our ability (choice) to act in the world (Critchley, 2009b). Accordingly, human beings are an ongoing "project", we are continually projected-thrown forward-in time. We choose how we how deal with our circumstances, authentically or inauthentically.

\subsection{Being-in-Language}

At the heart of Heidegger's ontology lurks a gnawing question: what is the connection between language and Being? Heidegger wants us to rethink language in a way that uncovers its essence as a showing, rather than regarding it as merely linking words to meanings. Pangaro (Pangaro, 1996) explains the way in which language allows us to make sense of the world, learn, and grow:

As observing beings, we learn what we learn by interacting with our environment: the spaces, objects, processes, and others-who-are-also-observing all around us... Metaphorically speaking, we "converse" with everything in our environment. We "offer our views" as we act, re-act and think. The environment "speaks to us" in the sense that we interpret it. We respond to what we hear and see and feel, in an exchange that has the structure of a dialogue in language.

Speaking, then, is not just an exchange of words; it is, more fundamentally, participating in a "saying" that is a showing; "what unfolds essentially in language is saying as pointing. Its showing does not culminate in a system of signs. Rather, all signs arise from a showing in whose realm and for whose purposes they can be signs" (Heidegger, 1993a).

What is the difference between saying what is true and showing what is true? Gelven (Gelven, 1989) contends that language shows the truth of Being; language states (says) the truth (facts) about entities. Truth about Being entails an unconcealment (unveiling) that draws meaning out into the open, whereas, in assessing whether an entity has a certain property, language states the truth (or it doesn't). If something is brought out into the open (disclosed) for the first time by way of language, then language itself must be that which uncovers meaning. InGadamer's words, "Human language must be thought of as a special and unique life process since, in linguistic communication, 'world' is disclosed...Language has no independent life apart from the world that comes to language within it” (Gadamer, 2005). Thus, language is our most important resource for interpreting the world; we cannot understand the world as we do apart from language. Hyde (Hyde, 1983) elaborates:

The revelation of Being is itself a linguistic experience; it occurs as objects of consciousness are interpreted such that they can be understood in a meaningful way. In this "making-known" of the object's meaning...Being is revealed through discourse...Discourse brings the word to mind such that [what is being interpreted] can be thought and eventually made-known to others through communication practices.

Heidegger wants us to distinguish between ordinary language and discourse. He emphasizes that discourse is what allows us to analyze the structures constitutive of Being. When he says that "the attuned intelligibility of being-in-the-world is expressed as discourse," he means that it is through discourse that we make sense of the world with others by "assenting, refusing, inviting, warning, as talking things through, as getting back to someone, interceding, furthermore as 'making statements' and as talking in 'giving a talk'” (Heidegger, 1996). Thus, discourse is constitutive of Dasein's existence; it discloses the Da (there) of Dasein (there-being) to Dasein through moods, interpretation (meaning), and communication. How are we to distinguish discourse-as a fundamental way of being-from the utility of language? According to Dahlstrom (Dahlstrom, 2013):

Discourse is an existential, a constitutive way of being-here that is disclosive of our being-here. To say that 
we exist as discursive beings is to say that, in and through our discursiveness, the meaning of being (i.e., being this or that, including ourselves) discloses itself to us, no less fundamentally than it does in the ways we find ourselves emotionally disposed in the world and in the ways we understand (project and work on) possibilities in our everyday lives...We may use language as a tool...to persuade others (or ourselves) of something but only because existential language, i.e., discourse-as a manner of being-here-reveals the world and our way of being in it to us.

Just as we always already find ourselves projecting ourselves onto some possibility or another in dealing with it, so we are always already speaking with ourselves and others in order to make sense of our circumstances and sort things out. When Heidegger writes that "language is the house of being," he means that our interpretation of the world and our way of being and acting in that world, is given to us by the contexts, meanings and ontological assumptions (assumptions about the way things are) embedded in the language we speak (Hyde, 1994). To be at home is to belong to Being; in disregarding the essence of Being we experience the angst of "not-being-at-home with one's self” (Heidegger, 1977). Heidegger wants to return us to our proper dwelling place, which is language. However, the house of being is not language in the everyday sense of symbols and words; rather, it is language as dialogue, which is most powerful when it is understood ontologically as the bringing into existence of possibilities (Nadal, 2010). "Language,” Heidegger claims, "is the clearing-concealing advent of Being itself...Those who think and those who create with words are the guardians of this home. Their guardianship accomplishes the manifestation of being insofar as they bring this manifestation to language and preserve it in language through their saying” (Heidegger, 1993b).

Said somewhat differently, "things show up [for us] in the light of our understanding of being" (Dreyfus, 1991). If our view of the world is that people are objects with properties, we will likely deal with them as transactions or as means to an end. If, however, we understand human beings as a "space" of possible ways of being and acting in and through which they can take a stand for what they care about most authentically, we will relate to them very differently.

\subsection{Being-in-Time}

The horizon (context) that grants us access to understanding Being-whether it's being a leader or being a parent-is time. Time, as used here, is not about ordinary measured (clock) time, with simply being at one point in time, at one "now" after another. Rather, it refers to our temporality— that we have a past we can revisit through our memories, a future that we are always living into, and a present that immediately becomes a past. Our temporality makes Being understandable, and thus makes it possible for entities (including ourselves) to make sense to us.

Dasein's temporal character is derived from a three-part ontological structure-existence, thrownness, and fallenness - inside of which Dasein discloses its Being (Heidegger, 1962; Dreyfus, 1991). For each of these structures, one temporal dimension is foremost. Existence refers to Dasein's potentiality-for-being, that it projects itself upon various possibilities for Being and, in so doing, is always living into a future. As thrown, Dasein always finds itself already dealing with something-some situation that has social, historical, and cultural underpinnings from the past. Thus, Dasein inherits its possibilities that are passed down to it by means of tradition from its ancestors. Finally, fallenness refers to Dasein's everyday being-with-one-another as "the they", having "fallen away" from itself and "fallen in" with the crowd.

Temporality is a movement through the world as a realm of possibilities. The "going back" to the possibilities that have been in the moment of thrownness (the past) and their projection in the resolute movement "coming towards" in the moment of existence (the future), which both take place in "being with" others in the moment of fallenness (the present), provide for the original unity of the future, the past, and the present which constitutes authentic temporality (Korab-Karpowicz, 2009). In our making sense of whatever every situation we happen to be thrown into, it is always unpacked, whether we realize it or not, using all three temporal dimensions. Wheeler (Wheeler, 2013) explains:

Dasein's beginning is thus a moment at which a biological human being has become embedded within a pre-existing world, a culturally determined field of intelligibility into which it is thrown and onto which it projects itself. Dasein's historicality has the effect of bringing the past (its heritage) alive in the present as a set of opportunities for future action. The idea here is not that I can do nothing other than repeat the actions 
of my cultural ancestors, but rather that, in authentic mode, I may appropriate those past actions (own them, make them mine) as a set of general models or heroic templates onto which I may creatively project myself.

It is our temporal nature that ultimately allows our potential authentic self to be realized. Essentially, the constraints and possibilities determined by our past are grasped in the present so that we may project ourselves into the future and create a future that is truest to our authentic self (Wheeler, 2013).

\section{What Does It Mean to Be a Leader?}

Building on the structures that constitute the "being" of human beings, we can ask, "What does it mean to be a leader?" Said otherwise, what are the implications of the existentials of human "being" for leaders and leadership? (Figure 3). The study of the phenomenon we call "leader and leadership" can be framed by two basic questions: 1) How does the leadership challenge I'm dealing with occur (show up) for me and how do I occur for myself in dealing with it? and 2) What mastery of the domain of leadership is necessary such that, in any and all circumstances, I can reframe (recontextualize) the circumstances I am dealing with such that my ways of being and acting optimize my effectiveness in tackling it?

\subsection{The Thrown Nature of Leadership}

Leaders always find themselves "thrown" into some set of circumstances that they must deal with. Many of these situations are unpredictable- they just happen. For Heidegger, all entities and events that we deal with are pre-interpreted by an understanding inherent in our already always being-in-the-world. He uses the word "understanding" to capture the sort of skilled mastery of practical situations embodied in our ways of projecting ourselves into possibilities for action (Krausz, 2002). A surgeon, for example, has a prior understanding of an operating room as a place where operative procedures are performed. The surgeon's preunderstanding "discloses" the operating room as a context that has an organized purposive manner but this happens without the constant accompaniment of a representational state that specifies what the action is aimed at accomplishing.

Heidegger contends that our intentional dealings with the world-objects, people, ourselves-are not necessarily mediated by mental content. In other words, notes Dreyfus, "intentionality without the experience of intentional content is characteristic of the unimpeded mode of everyday activity, whereas mentalistic intentionality is a derivative mode that occurs only when there is some disturbance, and we must direct our attention to the breakdown” (Dreyfus, 1993). He further explains in this somewhat lengthy but helpful quote:

[I] n everyday absorbed coping, ... acting is experienced as a steady flow of skillful activity in response to one's sense of the environment. Part of that experience is a sense that when one's situation deviates from some optimal body-environment relationship, one's...body is solicited by the situation to get into the right relation to it. When everyday coping is going well we experience something like what athletes call flow, or playing out of their heads. One's activity is completely geared into the demands of the situation. That is, one is absorbed in one's activity, and therefore one has no self-referential experience of oneself as causing that activity...[S]killful coping does not require a mental representation of its goal at all. It can be purposive without the agent entertaining a purpose...A huge amount of our lives-working, getting around, talking, eating, driving, etc.-is spent in this state, while only a small part is spent in the deliberate, purposeful, subject/object mode, but this is, of course, the mode we tend to notice....

Thus, as Antonsays, "pre-reflective experience remains largely holistic...This is not to deny our ever-present

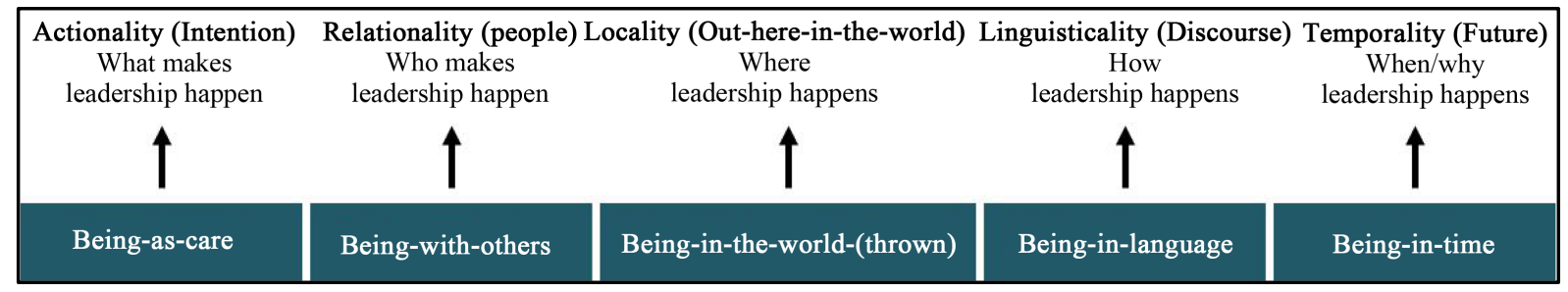

Figure 3. Incorporating the fundamental modes of human "being" into an actionable leadership structure. When the essential characteristics of the construct are mastered, it affords one the power to be a leader and exercise leadership effectively as one's natural self-expression in any leadership situation. 
resources for reflection and critical judgment, but it suggests that these are possible moments within a larger ongoing expressive, pre-thetic [pre-reflective] field of communicative praxis” (Anton, 2014). Reflective experience is called into play when we encounter a complication or hurdle: for example, a leadership challenge we have not previously dealt with, a seemingly insurmountable budget challenge, or an employee who commits a felony. In these instances, "what had been largely tacit or transparent becomes explicit and opaque. During such moments of breakdown, we experience an increasing degree of explicitness with regard to what previously is in the background. Time flow suddenly becomes constricted and pulverized into isolated bits and is thrown back upon itself, made subject to thematic, analytic reflection” (Anton, 2014).

Heidegger does not deny the intentional nature of our directed actions. He does, however, contend that the everyday notion of action conceals our most basic mode of involvement in the world. He uses the term "comportment" to refer to our directed activity with no mental component. Comportments have the structure of directing-oneself-toward, projecting ourselves onto our "thrown situatedness." Taking responsibility for one's "thrownness" is the cornerstone of authentic leadership. Rather than fleeing from their "thrownness," authentic leaders accept responsibility for whatever breakdowns or failures occur on their watch. They do not dodge or sidestep their challenges. To live authentically means to be, regardless of the situation we are thrown into, answerable for what is and accountable for creating a viable future. Hyde (Hyde, 1994) elaborates:

The authentic [leader] is not one that has managed to escape the everyday thrownness of human being; rather, it is a [leader] that has taken hold of that thrownness "in its own way". [The leader] has appropriated the everyday way of being, recognized it, allowed it, and owned it, rather than continuing to be owned by it.

Our moment-to-moment, situation-to-situation way of being and acting matches the way in which the leadership challenge we are dealing with occurs for us and the way in which we occur for ourselves in tackling it. If the situation I'm dealing with occurs for me as hopeless, my way of being and acting will be consistent with hopelessness. If the situation occurs for me as one I can tackle and I occur for myself as competent, my way of being and my actions will be correlated with that "occurring”. Effective leaders have learned to recontextualize (reframe) their leadership challenges so they show up as "hittable" (Souba, 2011). Because we live in language, we have jurisdiction over how we listen to and "be" with whatever situation we are dealing with. This choice powerfully impacts life's hittability and our effectiveness as leaders.

Because these challenges can be intimidating, even overwhelming, leaders must constantly be aware that their beliefs and assumptions largely determine the decisions they make and the actions they take. Beliefs are not facts but we tend to hold them as if they represented the truth for us. We must therefore challenge them by looking beneath them to find the contexts that propagated them (Douglas \& Wykowski, 2010). A phenomenological inquiry allows us to "unconceal" the hidden contexts that frame the decisions and actions that determine our leadership performance.

While our beliefs and the contexts that frame them are, by and large, deeply-engrained, they invariably were constituted in language. Similarly, it is through language that we disassemble these hidden points of view, a process that sometimes entails "jarring us loose" from the comfortable, engrained, hidden beliefs and points of view that can limit our leadership performance. Leaders use language to reframe their challenges such that their natural self-expression spontaneously emerges. What you create in language "uses you" by providing a point of view (a context) within which you "know" reality and orient your actions (Boje, Oswick, \& Ford, 2004). Hyde (Hyde, 1983) explains:

How is Being [a leader] revealed to man in and through the lived experience of his [leadership]? ...The revelation of Being is itself a linguistic experience; it occurs as objects of consciousness are interpreted such that they can be understood in a meaningful way. In this "making-known" of the object's meaning... Being is revealed through discourse... Discourse brings the word to mind such that [what is being interpreted by the leader] can be thought and eventually made-known to others through communication practices.

Recognizing that many of our problems are inevitable, exceptional leaders have learned how to experience life - the world, others, and themselves — and its problems differently than most of us do. They are facile at exposing their reigning (hidden) contexts, which allows them to identify their unexamined beliefs and taken-forgranted assumptions that color the situation they're dealing with, and their implicit theories of what it is to be a leader and what it is to exercise leadership effectively. Accordingly, they deal with life differently than most of us do. What allows these individuals to interact with and deal with life's challenges differently than most people 
do is that the source of their leadership arises from a unique language that is heavily based in phenomenology. This allows them to recontextualize their challenges as needed such that their actions translate into greater effectiveness.

This is the task of leadership—-to break free from our conventional ways of leading and to recognize that individual transformation must parallel organizational transformation. Personal transformation is about creating access to a broader range of ways of being, thinking, and acting in order to be more effective in dealing with those challenges for which conventional strategies are inadequate.

\subsection{Leadership as Being-with-0thers}

Dasein, "as being-with-[others], is essentially for the sake of others" (Heidegger, 1977). This is invariably the case with exemplary leadership. Our best leaders are always committed to improving the lives of those they serve, which includes both customers and employees. In Dahlstrom's words, "we only exist authentically when we exist for [others'] sakes in our concrete, historical situations...The meaningfulness of the world...coincides with being for-the-sake-of others" (Dahlstrom, 2014).

We cannot be human on our own; we can only be human through others. Leadership is born out of relational spaces created by building high-powered human connections grounded in awareness, integrity, authenticity, and commitment (Figure 4). Strong, trusting relationships are crucial, especially during times of major disequilibrium and change. "Drive out fear" quality guru W. Edwards Deming (Deming, 1986) emphasized over and over. When people are afraid of contradicting their bosses or afraid of being labeled a rabble-rouser if they say what's on their mind, organizational performance suffers. Curiously, leaders who encourage straight talk are more respected because it demonstrates that they know they don't have all the answers. When the untalkable becomes talkable, it strengthens the bonds (commitment, trust) that hold people together in the midst of the pressure, heat, and explosiveness that can arise in tough conversations.

Conversations in every organization are guided by a set of (mostly) implicit rules, which circumscribe what may be discussed, and what may not. Interestingly, most of the time the capacity needed to thoughtfully discuss the undiscussables already exists in the organization. But with no formal venue to get the issues out in the open, the default venue becomes the restroom and the water cooler.

The Law of Requisite Variety states that the survival of any living system depends on its capacity to cultivate and embrace variety and diversity in its internal environment (Pascale, Milleman, \& Gioja, 2000). This theory has important implications for organizations. Since the variety of perturbations a system can potentially be confronted with is virtually unlimited, the organization should always try to maximize its internal variety (or diversity), so as to be optimally prepared for any foreseeable or unforeseeable contingency. In essence, this prepares the organization to deal with change.

\subsection{Leadership as Care (Action)}

Leaders reveal their care by projecting themselves onto their thrown circumstances and taking on their leadership challenges. Action is the currency of leadership. Without action-speaking, allocating resources, saying no, writing a business plan, etc.- - leadership does not happen. Only action produces results (whether intended or un-
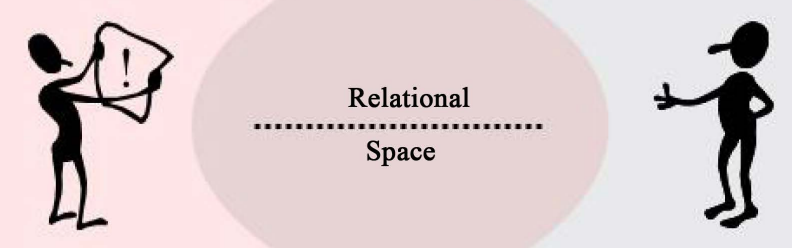

Figure 4. Leadership as being-with-others. Leadership is born out of relational spaces created by building high-powered human connections grounded in awareness, integrity, authenticity, and commitment. 
intended). Mastering leader and leadership as a range of possible ways of being and acting leaves you free to be and free to act in any way, rather than being constrained by common notions, taken-for-granted ideas, and the latest fads about what it is to be a leader and what it is to exercise leadership effectively (Erhard et al., 2011).

Something that is projected on or at something else is said to have "intentionality". Intentional action includes both neural circuits in the brain and also a conscious experience that "I" am the source of the action. The intentionality of an action refers to it being deliberate, thoughtful, and goal-oriented. Dreyfus describes a fundamental dichotomy between what he calls "two distinct kinds of intentional behavior: deliberative, planned action, and spontaneous, transparent coping” (Dreyfus, 2002a). Intuitive absorbed coping is prominent at "high levels of expertise, whether in sport, chess, nursing, or driving, [such that] action management and decision-making do not even appear as problems for the expert practitioner [master]" (Sutton et al., 2011). This "coping" is clearly action, rather than involuntary reflex reaction to stimulation, and involves learned sequences of movement—but it does not require any deliberation or planning in advance and does not occupy attention while occurring (Webber, 2002).

When there is a breakdown in our leadership effectiveness, it is wise to reflect on what went wrong (and what's gone right). Solutions, however, are rarely solely technical in nature. Fixing a malfunctioning wristwatch or photocopier is relatively straightforward but fixing ineffective leadership is much more complicated because our implicit leadership theories (what works and what doesn't) are so engrained and long-standing. In contrast to technical problems, leadership challenges are difficult to resolve but easy to avoid. The work of leadership is required when our deeply held beliefs are challenged, when the values that made us successful are less relevant, and when legitimate yet competing perspectives emerge (Heifetz \& Laurie, 2001). Thus, leadership challenges can only be solved by people learning new ways of working them. Failure to differentiate technical problems from adaptive challenges may be the single most important reason for leadership failure today.

Our enslavement to the "they" often prevents leaders from seizing their possibilities for Being (and acting). What frees us from this default stance is what Heidegger calls the "voice of conscience". It is conscience that calls its own Being into potentiality for authenticity, which becomes manifested as care. This care is most powerful when it is about a future that is bigger than any personal agenda. Such a commitment initiates being and action in the present such that the problems the leader might encounter along the way in delivering that future show up for them as "this just is" rather than insurmountable roadblocks.

As Heidegger says, "The call of conscience - that is, conscience itself-has its ontological possibility in the fact that Dasein, in the very basis of its Being, is care" (Heidegger, 1996). The call silences the "they" and calls leaders to authenticity, with the outcome being that they take responsibility for their thrown situatedness. Understanding and heeding the call is a way being, a way of being that is matched by a way of acting.

\subsection{Leadership Lives in Language}

In a very real sense, an organization is most fundamentally a labyrinth of conversations between people. Pangaro (Pangaro, 2002) contends that "by continually changing its language-and its conversations - an organization may continually regenerate itself [by acquiring] new, relevant language domains...The structure of an organization's language is directly related to the structure of its culture. Culture creates language, and language shapes culture. An organization's ability to create language is synonymous with its ability to evolve.”

Language functions as an essential tool that leader's use to communicate, describe, inform and set direction. Pinker (Pinker, 2000) claims that everything linguistic is fundamentally grounded in two complementary phenomena, words and rules. Words are the link between an utterance and a thought. But we don't randomly ejaculate our words; instead, we arrange them into phrases and sentences such that meaning can be inferred from the way in which they are combined. Without either one, fathomable speech is not possible. But even when choose the "right" words and use the proper rules, the spoken message is inevitably imprecise. Gaines (Gaines, 2003) explains why:

Communication is necessarily ambiguous because, through the representational processes of perceiving an expression of objects, events, or ideas, meaning is mediated in the mind of an interpreter...Truth in human communication is ambiguous at best because the interpretation of a receiver may only approximate the intent of a speaker. Objects and events in the natural world exist without a necessary intent or meaning. Language, based upon symbols intended to represent conventional understandings, is necessarily ambiguous.

For leaders, language is not simply an utterance; it is also "the clearing-concealing advent of Being itself" 
(Heidegger, 1993b). In other words, "language alone brings what is, as something that is, into the open for the first time. Where there is no language..., there is also no openness of beings...Language, by naming beings for the first time, first brings beings to word and to appearance. This naming nominates beings to their Being and from out of that Being-in shaping the way in which things (people, situations, ideas) occur for and matter to us, language allows "the thing-in-itself to come into the fullness of its being" (Heidegger, 2002). Language has the ability to bring forth, out of the unspoken realm, innovative ideas and possibilities.

While language is the principal shared symbol system through which meaning is created and communicated, "words often mean more than they mean...The surplus meaning is phenomenological when the meaning is evocative of lived experience, when it re-awakens some possible human experience in a manner that is immediate and yet prompting reflection. Thus language is a source of meaning; it makes our experience 'recognizable"” (Van Manen, 2011). For example, the phenomenological study of leadership reveals commonly held long-standing beliefs associated with the word "leadership". We tend to think of leadership as being about a person in charge who stands apart. The word "leader" is often associated with vivid images: the gifted innovator; the charismatic chief executive; the superb teacher; the bold entrepreneur. By and large, our view of leadership tends to center around visible individuals and their talents, achievements, and clout. Is this prevailing view of leadership the way in which leadership is best understood in the $21^{\text {st }}$ century?

Most speech describes or explains the properties (characteristics) of entities. Conversely, to speak as showing is to let language reveal ("unconceal") meaning. Discourse brings matters (issues, problems) out into the open so that they can be seen, made sense of, and tackled. Truth requires first and foremost a "letting be seen". Primordial truth as "letting be seen" creates the opening that allows propositional "truth" to be determined as correct or incorrect. Things do not appear in and of themselves. They are revealed to someone. Strong leaders create distinctions in language that nudge us to revise our mental maps of the world. In so doing, they shift the context and prepare the organization for new actions.

Moore pointed out more than 100 years ago that "talk is cheap, and it is one of the few luxuries many of us can afford; nevertheless the man whose perpetual loquacity converts him into a nuisance should be required to hire a hall, where he could talk to himself without disturbing his fellow creatures” (Moore, 1909). However, good leaders know that talk is not cheap. They recognize that language is the bridge between the created present and the uncreated future, which affords them the opportunity to transform others. Language is especially powerful for tackling challenges that rely heavily on conceptual, innovative solutions as opposed to those problems that are simple and technical in nature (Souba, 2010). Rather than spending all their time in the domain of content, where issues are understandable, they situate their complex leadership challenges within an appropriate conversational context to provide a basis for action. Leaders do this by creating linguistic distinctions that prompt cognitive shifts in others, jarring them loose from their entrenched worldviews. This requires using language that enables people to create meaningful images as they speak. "The difference between the almost right word and the right word," observed Mark Twain (Twain, 1888), "is really a large matter-it's the difference between the lightning bug and the lightning." Small differences in the words we use can create big differences in sense-making.

Thus, language (communication) is not merely symbolic but first and foremost constitutive. In other words, speech is firstly consequential and secondarily referential (Anton, 1999). Leaders know that human meanings are not given beforehand in an objective, prelinguistic realm, and then re-presented in words; rather language itself, at work in the interactions of daily human existence, adds the meanings, and in so doing shapes the world (Souba, 2010). In the quote below, Richard Rorty (Rorty, 1986) eloquently articulates that truth does not exist independent of the human mind:

We need to make a distinction between the claim that the world is out there and the claim that the truth is out there. To say that the world is out there, that it is not our creation, is to say, with common sense, that most things in space and time are the effects of causes which do not include human mental states. To say that truth is not out there is simply to say that where there are no sentences there is no truth, that sentences are elements of human languages, and that human languages are human creations. Truth cannot be out there - cannot exist independently of the human mind - because sentences cannot so exist, or be out there. The world is out there, but descriptions of the world are not. Only descriptions of the world can be true or false. The world on its own — unaided by the describing activities of human beings—cannot.

Rorty contends that "we are nothing save the words we use"- there is no behind the scenes choreographer, 
there is just us and the words we choose. Recognizing this, leaders stress to others the importance and power of language. They are aware what Fritz Perls refers to as the three kinds of conversational "shit" that we are likely to encounter while talking with people (Lung, 2011). Chicken-shit is clichéd small talk that is devoid of actual information content and avoids emotional contact (for example, Hi-how's-it-going-nice-day-how's-the-familygood-to-see-you). Bullshit talk refers to out-and-out lies that are told to conceal the truth, protect someone, and/or gain something. Bull shitters are opportunists; they tell falsehoods to promote themselves and their agenda. Elephant-shit talk refers to grandiose plans that the conversationalist has no hope of fulfilling because the ideas are unrealistic.

Similarly, much of our thinking is calculative in nature, focusing how best to achieve whatever goals we may have. Reflective thinking, which takes into consideration of one's own learning by assessing one's achievements and failures, is all too uncommon. Heidegger (Heidegger, 1966) is clear that we are still not thinking critically:

"[M]an today is in flight from thinking...[P]art of this flight is that man will neither see nor admit it. Man today will even flatly deny this flight from thinking. He will assert the opposite. He will say—and quite rightlythat there were at no time such far-reaching plans, so many inquiries in so many areas, research carried on as passionately as today."

In revealing to others the power of thoughts and words in creating new futures, leaders enhance the quality of the thinking and the conversations that define the organization. In contrast to most of our thinking, which is automatic or reactive, "called thinking" (Heidegger, 1968) is a particular kind of thinking which calls forth the thought out of the circumstances one is dealing with. It involves being present with the leadership situation so as to let it be summoned to experience in thinking. It is to let a leadership challenge call forth the thought rather than saying something automatically.

\subsection{The Futuralness of Leadership}

All of our experiences as leaders have a common temporal structure: a reference to past experiences, a current openness to what is present, and an anticipation of the experiences that are about to happen (Gallagher \& Zahavi, 2014). How we make sense of our leadership challenges and the possible strategies for dealing with them always occur for us in and through the context of the future we are living into. In other words, both the issues at hand, and the possibilities for dealing with them, occur for you in the context of the future you are living into. As formidable and complex as your leadership challenges might seem today, if they occur for you as "hittable" and you occur for yourself as competent, the result will be a context in the present that will enhance your effectiveness.

As a leader, creating a new future for your organization often means reinventing yourself. Every system—the human operating system is no exception-is built exactly to get the results it gets. Since every system also has a design limit, a jump in performance entails new ways of being and acting. Without something akin to a transformation, your future is likely to be a continuation of your past.

Time is the medium inside of which we understand and interpret something like "being a leader". Drawing from Blattner (Blattner, 2005), understanding yourself as a leader is not about bringing about some possible, future state of yourself. The possibility of being a leader is not an end-state or goal; it is not something that you "someday will be". Of course, you can have attained the prestige and status of being a leader: the prerogatives, responsibilities, and entitlements that are generally accompany carrying such a position or rank. Status, however, is not the same as an ability-to-be.

The term "futural" does not refer to some point on a calendar or timetable next week or next year at which time a leader will be born or a strategic plan will be complete. Rather, it refers to one of the fundamental structures constitutive of Dasein's being - “its movement toward its self-definition, its 'coming toward' itself...The idea seems to be that our striving to accomplish things in practical affairs is part of our underlying striving to be something as humans - to realize and define our identity (or being) as such and such, that is, to make something of ourselves in what we do" (Blatter, 2005).

What's critical to being an effective leader is that the future you are living into is about a commitment that's bigger than you are, the realization of which fulfills what you authentically care about. Committing to such a future will give you the power, freedom, and natural self-expression to lead effectively in dealing with the circumstances present in your life right now. This temporality is why leadership can happen. However, when leadership happens is always and only now, as Alan Watts (quoted in Jacquin, 2013) states so poignantly: 
We are living in a culture entirely hypnotized by the illusion of time, in which the so-called present moment is felt as nothing but an infinitesimal hairline between an all-powerfully causative past and an absorbingly important future. We have no present. Our consciousness is almost completely preoccupied with memory and expectation. We do not realize that there never was, is, nor will be any other experience than present experience. We are therefore out of touch with reality.

The moment-to moment, situation-to-situation "being" of leader and leadership only fully reveals itself to you when you are present, right now. Being in the "now" liberates you from the bondage of your past. In the moment of your presence, possibilities will spring forth and obscurity will morph into clarity. The facts of the circumstances you are dealing with will be what they are, but they will have no inherent significance; they will have only the meaning you ascribe. The future then is wide open for you to create.

\section{Unleashing the Leader within}

Much as scientists apply critical thinking to their research questions, leaders must do the same in examining the puzzle called "me and my leadership." A sincere deep dive into this conundrum requires that we confront our average everydayness and "our resistance to authentically face our everyday conformity which entraps our curiosity and our fate” (Gibbs, 2011). Smythe and Norton (Smythe \& Norton, 2007) elegantly describe this predicament:

The leader who stays "safely" in the realm of the veiled and the sheltered, who stays on the known paths, is unlikely to lead others to new ideas, to new territory or towards a new vision...It takes courage to leap and it takes wisdom to reside in the new found territory of thinking where everything is different. One can only "play" in a context where there are no known ways, no preformed rules and no policy guides.

With the burdens of the human condition-our thrownness and anxiety-one escape route is to defer to the "they." We do what "they" do because "that's the way we do things around here." In short, we conform. We become prisoners of what "they" will think. "Most people are other people;" points out Oscar Wilde (Wilde, 1964); "their thoughts are someone else's opinions, their lives a mimicry, their passions a quotation." When we live inauthentically, we lose sight of others as Dasein instead, they become objects with properties, means to an end. There is little to no dialog; there is almost exclusively idle talk. We slip into a mode of Being in which we conform and go with the flow. Why do we allow this to happen? Soccio (Soccio, 2007) unpacks our tendency to follow the crowd and conform:

We encourage it in our flight from the burden of being human, our flight from substantive, existential freedom and choice. We encourage it as a way of evading the hard decisions of what aspects of life to put aside and what to pursue. Instead of struggling with how and what to be, we focus on what to do. What we are supposed to do has been predetermined for us by the "they".

Only when leaders are willing to take a stand for what they care about deeply can they address what it means to be a leader. "The question of Being," writes Polt, "attempts to recover the disquiet of the human condition as a fragile and fallible sojourn within the inexplicable unfolding of meaning and truth—a disquiet that is ordinarily anesthetized by the scientific and technological mind-set of our age” (Polt, 2005). For the most part, we have coped with our Being-in-the-world as being in a galleria of sorts, where we acquire things to add to our possessions. Might our existence be less about having or possessing objects and more about a way of being or an experience of being?

Whether or not we know it, we exist in some mode of a possibility called "clearing", a metaphorical space in which we can "be". It is a space in which Being itself can come to be more fully, show itself more wholly, and become more present in the world. This disclosure of the authentic self always involves a "clearing-away" process that creates a clearing-for-action in which the leader is free to be and free to act, rather than being constrained by conventional notions about what it is to be a leader and what it is to exercise leadership effectively (Erhard et al., 2011). According to Gibbs (Gibbs, 2011), this space of being provides.

A glimpse of how we might transform ourselves from being in a state of falling (inauthentically busying ourselves in our world) to one of resoluteness (taking a personal stance and being open to a life with no intrinsic, only relative meaning)... and to respond in a way that reflects on the potentiality within our way of 
being that we have overlooked or abandoned.

Most leaders lead according to (consistent with) some set of principles or some list of do's and don'ts, rather than dealing with their leadership challenges as they actually encounter them: practically, as-lived, and commonsensically. As a result, they attempt to understand and accomplish leadership as it is encountered through these procedural theories and rules. One of the most common ways we interact with life is based on causal determinism, which says that every event is initiated by antecedent events and conditions (Hoefer, 2010). Causal reasoning is the ability to identify causality: the relationship between a cause and its effect. What caused the (good or bad) outcome? Who is culpable? Who dropped the ball? Cause-and-effect relationships give reasons and explanations for incidents, circumstances, or conduct but they give us limited access to leadership as-lived. Explanations and beliefs satisfy the need most of us have to understand the world around us. Erhard (Erhard, 2009) nicely conveys the inherent limitations:

The prevailing model of performance says that performance is an effect, where the cause of that effect is the internal characteristics and attributes of the performer, now better explained by neuronal processes, and/or, the external circumstances with which that performer is confronted...The prevailing model of performance constrains and shapes our current practices for creating or transforming performance to one of an attempt to alter the internal characteristics and attributes of the performers, or now their neurological processes, and/or attempting to alter the external circumstances with which those performers are confronted.

Our beliefs inevitably shape the way in which we confront and tackle our leadership challenges because our beliefs always contribute to the contexts that shape and color the way in which our challenges occur for us. Most of the time, we are unaware of our belief systems because we are engrossed in the unconscious, absorbed coping of our day-to-day living. Even so, our beliefs can be inconsistent with our "as-lived" experiences. Indeed, the very nature of belief precludes the necessity of experience. For example, some people believe that extroverts make better leaders than introverts, a belief which may be independent of experience.

When we are confronted with a leadership challenge that we haven't encountered before or one that occurs for us as "unhittable", intimidating, or threatening to our identity, our absorbed coping is interrupted. We must pause and mull things over, a process that requires sober phenomenological reflection in order to grasp the meaning of what we're dealing with. Our thinking should be rigorous, and as much as possible, free from theoretical, prejudicial and suppositional intoxications (van Manen, 2014). But our conscious experience of the leadership challenge at hand that we must tackle—what it is like for us, its "aboutness" — may be ambiguous. At the same time that the situation is unfamiliar and difficult to size up, we are often under pressure and time constraints. Under these circumstances, we tend to default to our beliefs and explanations as the basis of our decision making. This is not surprising, as Lester (Lester, 2000) notes:

Because beliefs are designed to enhance our ability to survive, they are biologically designed to be strongly resistant to change... Functionally, our brains treat beliefs as internal "maps" of those parts of the world with which we do not have immediate sensory contact...This is the area of abstractions and principles that involves such things as "reasons", "causes", and "meanings".

When we are leading in our "absorbed, skillful coping" mode, the source of our moment-to-moment, situation-to-situation way of being and acting (our behavior) is its naturally existing "entangoment" with the way in which the situation we are dealing with occurs for us and the way we occur for ourselves in dealing with it (Souba, 2011). Said somewhat whimsically, “when things are proceeding normally, experts don't solve problems and don't make mistakes; they simply do what experience has shown normally works, and it normally works" (Dreyfus \& Dreyfus, 1996). However, this absorbed activity "is not determined by us as someone standing outside the situation simply looking on at it; what occurs and is imposed are rather prescribed by the situation and its own structure; and we do more and greater justice to it the more we let ourselves be guided by it, i.e., the less reserved we are in immersing ourselves in it and subordinating ourselves to it. We [are] just 'absorbed' into it” (Gurwitsch, 1979). As basketball great Larry Bird said: "A lot of times, I've passed the basketball and not realized I've passed it until a moment or so later” (Levine, 1988).

A breakdown occurs when our ongoing absorbing coping is interrupted by something unexpected. When the pen I am using quits working, I am forced to pay purposeful attention to it, whereas before I didn't think twice 
about its workability. In other words, "when there is a serious disturbance and even deliberate activity is blocked, Dasein is forced into still another stance, deliberation. This involves reflective planning. In deliberation one stops and considers what is going on and plans what to do, all in a context of involved activity” (Dreyfus, 1991).

When the pen I'm writing with quits working, the breakdown (malfunction) is self-evident and I can access another pen. But if my leadership—my way of being a leader and exercising leadership—breaks down and I'm not as effective as I need to be, I can't replace myself (my boss certainly can). I need to find more effective ways of being and acting in order to tackle the challenges at hand. In these types of situations-which are common because leaders face breakdowns routinely-a phenomenological inquiry allows leaders to call into question the veiled beliefs and assumptions that determine the decisions they make and the actions they take. When these contexts become unveiled, it allows for the creation of new contexts that give leaders more space and degrees of freedom to lead more effectively as their natural self-expression.

When they experience a breakdown, leaders' tend to unwittingly default to a set of beliefs and theories to determine their way of being and acting rather than letting the naturally existing correlation-the "entangoment" -between the challenge at hand and the leader's behavior be the source of their ways of being, thinking and their actions (Souba, 2011). Leaders may begin to see themselves as a set of fixed behaviors rather than as human beings whose life is experienced "as-lived and lived through.” Laing (Laing, 1967) cautions us when he says:

To identify oneself with behavior is to become alienated from one's own experience...If our experience is destroyed, our behavior will be destructive...If you are truly living from experience, from the unlimited capacity to grow, learn and evolve, then you will be continually transcending the limits of behavior. In conventional terms, the most obvious sign of behavior is habit, custom, the usual way of doing things. It represents a form of conditioned response induced or programmed from outside. Such conditioning works against the innate capacity for experience.

While expert performance (being in your "A" game) is, for the most part, ongoing and non-reflective, the best leaders think before they act. But, they uncommonly think about theories or concepts when making judgments. Much more frequently, the process is intuitive and meditative, what Dreyfus calls "deliberative rationality," which can be described as reasoned observation of one's intuitive, practice-based behavior without replacing it by the purely theory-based action of the apprentice (Dreyfus \& Dreyfus, 1996). Inexperienced leaders, on the other hand, revert to a kind of inferential thinking, "calculative (instrumental) rationality", which is grounded in a more technical set of rules, theories, and/or explanations. Mastery, it seems, only comes about when the expert leader no longer leads from a set of theories and is no longer consciously attending to his or her performance. When this happens, it frees up the leader's cognitive capital previously directed towards monitoring and measurement to be invested in creating the appropriate "entangoment" and its associated action.

The increasing complexity of our global leadership challenges and their attendant breakdowns is amplifying the risk that, in the future, mastery will be lost through overreliance on calculative rationality. Calculative rationality, which is sought for good reasons and is absolutely necessary, means a loss of expertise (Dreyfus \& Dreyfus, 1996). In complex coping domains such as leadership, practice without theory is invariably inadequate. But if you could only have one, choose the practical experience. In the domain of mastery there is no leadership knowledge (as Dreyfus might define it) but there can and must be leadership understanding and wisdom. Thus, in leading, one discovers that the practice of leading requires a strong element of tacit involvement for which there can be no theory.

Being a leader is not an end-state that we attain; it is not something that we at some point will be. In acquiring progressive competence, leaders normally move through developmental stages (Table 3). It appears that as leaders become more and more capable, they depend less on abstract principles (third-person) and more on firstperson concrete experience (Dreyfus \& Dreyfus, 1980).

Ludwig Wittgenstein (quoted in Rhees, 1984) once remarked that "If anyone is unwilling to descend into himself because this is too painful, he will remain superficial.” Personal transformation is experienced by most people as difficult if not agonizing work (Souba, 2006). But we must take it on if we want to change the world.

\section{Implications for Leadership Development}

There is a prevailing, yet hidden, perspective on societal transformation that assumes if we change society-by instituting laws, rules, penalties, and incentives-human beings will ultimately change. This assumption is flawed. 
Table 3. The progression of leader and leadership development.

\begin{tabular}{|c|c|c|c|c|c|}
\hline & $\begin{array}{l}\text { Novice } \\
\text { (Rookie) }\end{array}$ & $\begin{array}{l}\text { Advanced } \\
\text { Beginner }\end{array}$ & $\begin{array}{l}\text { Competent } \\
\text { Performer }\end{array}$ & $\begin{array}{l}\text { Proficient } \\
\text { Performer }\end{array}$ & $\begin{array}{l}\text { Expert } \\
\text { (Master) }\end{array}$ \\
\hline $\begin{array}{l}\text { Implicit } \\
\text { leadership } \\
\text { theory }\end{array}$ & $\begin{array}{l}\text { A person in charge } \\
\text { who wields clout }\end{array}$ & $\begin{array}{l}\text { A person with } \\
\text { a compelling } \\
\text { vision }\end{array}$ & $\begin{array}{l}\text { A person who } \\
\text { takes a stand for } \\
\text { the future }\end{array}$ & $\begin{array}{l}\text { A systemic } \\
\text { capacity that } \\
\text { aligns people }\end{array}$ & $\begin{array}{l}\text { An exercise in } \\
\text { language that } \\
\text { shifts the "occurring" }\end{array}$ \\
\hline $\begin{array}{l}\text { Use of the } \\
\text { language of } \\
\text { leadership }\end{array}$ & $\begin{array}{l}\text { Token fluency with } \\
\text { leadership terms/words }\end{array}$ & $\begin{array}{l}\text { Conversant with } \\
\text { concepts and } \\
\text { definitions }\end{array}$ & $\begin{array}{l}\text { Uses language } \\
\text { of phenomenology } \\
\text { in conversation }\end{array}$ & $\begin{array}{l}\text { Conversational } \\
\text { domain discerned } \\
\text { in the first-person }\end{array}$ & $\begin{array}{l}\text { Conversational } \\
\text { domain "uses" } \\
\text { the leader }\end{array}$ \\
\hline $\begin{array}{l}\text { Response to a } \\
\text { leadership } \\
\text { breakdown }^{*}\end{array}$ & $\begin{array}{l}\text { Often confused, } \\
\text { clueless, if not lost }\end{array}$ & $\begin{array}{l}\text { Calculative } \\
\text { rationality }^{* *}\end{array}$ & $\begin{array}{l}\text { Calculative } \\
\text { rationality }\end{array}$ & $\begin{array}{l}\text { Calculative } \\
\text { rationality }\end{array}$ & $\begin{array}{l}\text { Deliberative } \\
\text { rationality }^{* * *}\end{array}$ \\
\hline $\begin{array}{l}\text { Theory of } \\
\text { performance } \\
\text { (effectiveness) }\end{array}$ & $\begin{array}{l}\text { Performance is an } \\
\text { effect caused by } \\
\text { the leader's } \\
\text { traits/attributes }\end{array}$ & $\begin{array}{l}\text { Performance is } \\
\text { an effect caused } \\
\text { by the leader's } \\
\text { traits/attributes }\end{array}$ & $\begin{array}{l}\text { Performance is } \\
\text { an effect caused } \\
\text { by the leader's } \\
\text { traits/attributes }\end{array}$ & $\begin{array}{l}\text { Performance is } \\
\text { predominantlya } \\
\text { correlate of } \\
\text { the "occurring" }\end{array}$ & $\begin{array}{l}\text { Performance is } \\
\text { predominantlya } \\
\text { correlate of the } \\
\text { "occurring" }\end{array}$ \\
\hline
\end{tabular}

*A disruption in the leader's absorbed coping; ${ }^{* *}$ Deferral to a familiar set of rules, theories, and/or explanations (theory-based action); ${ }^{* * *}$ Reasoned observation of one's intuitive, practice-based behavior (leadership “as-lived”).

Leonard Joy (Joy, 2002) reminds us that societal transformation is inconceivable without the personal transformation but changes in individual behaviors will meet severe constraints to societal progress unless there are sufficient numbers willing to question institutional behaviors and mores. Individual transformation it is not a lagging indicator; the uncomfortable truth is that individual transformation must parallel the transformation of our organizations and communities (Souba, 2014). Failure to recognize this indissoluble relationship has contributed significantly to the struggles that we encounter with our leadership challenges today. This lapse may explain the dearth of scholarship on the science and practice of leading oneself in the peer-reviewed literature.

We often recognize the complexity of our leadership dilemmas and we understand that technical solutions alone are insufficient. But we generally fall short in preparing people for what it will take to tackle really complex challenges. Many transformation efforts are unsuccessful because they overlook the importance of personal transformation in enabling major systemic change. Personal transformation is about creating access to a broader range of ways of being, thinking, and acting in order to be more effective in dealing with those challenges for which conventional strategies are inadequate. New ways of being and acting can only be disclosed using a phenomenological approach to leadership.

Some people maintain that the "softness" and "imprecision" of the human sciences makes it difficult to study leadership and draw definitive conclusions. Granted, leadership is as much an art as a science. But, "the claim that the human sciences are methodologically retarded and should adopt the exact method of natural science is unfounded...Because the phenomena studied by the natural and human sciences are different, different methodologies are called for. Natural science aims to discover the nature of unconscious physical matter in all its forms. [The human sciences] study meaningful phenomena: social interactions, experiences, thoughts, intentional actions...- - everything that involves human beings qua self-conscious beings” (Ingthorsson, 2013).

The way we "make sense" of the phenomenon we call leadership will inform and shape the way in which we develop leaders. If we continue to understand leadership as being, first and foremost, about what leaders know and do, the emphasis will be on acquiring more knowledge, more expertise, and more credentials. While know-what, know-how, and the theories that underlie them are important, they must be anchored in a foundation that begins with what it is to be a leader. Here, phenomenology is most valuable because it approaches life as it is lived, that is, from a practical and intuitive first-person understanding, rather than from a set of abstract theories and concepts.

The term "conversational domain" refers to the specialized linguistic terms that define a particular field of expertise or study (e.g., leadership). This shared language allows practitioners in a specific knowledge discipline-e.g., phenomenology, geology, or philosophical mathematics-to communicate with other members in their field and innovate. This paper argues that creating for oneself what it is to be a leader entails mastering a special language of phenomenology as it relates to leadership (Table 4).

Schön (Schön, 1983; Schön, 1987) talks about the notion of "dialoguing with the material at hand" that is part 
Table 4. Some phenomenological terms and their relevance to leadership.

\begin{tabular}{|c|c|}
\hline Term & Relevance to Leadership \\
\hline Phenomenology & $\begin{array}{l}\text { Phenomenology is the "as-lived" study of the various challenges that leaders deal with and the way in which } \\
\text { these phenomena are experienced from the first-person point of view. }\end{array}$ \\
\hline $\begin{array}{l}\text { Hermeneutic } \\
\text { (interpretive) } \\
\text { phenomenology }\end{array}$ & $\begin{array}{l}\text { The name given to phenomenology that claims that leaders cannot fully bracket their biases and assumptions } \\
\text { when they "unpack" a leadership challenge because these biases and assumptions are never independent of } \\
\text { their history, culture, and social context. We experience a thing as } \\
\text { something that has already been interpreted. }\end{array}$ \\
\hline $\begin{array}{l}\text { Existentials of human } \\
\text { "Being" }\end{array}$ & $\begin{array}{l}\text { Existentials are characteristics (structures) of human "Being" that are revealed by the analysis of its existence. } \\
\text { These structures-being-in-the-world-(thrown), being-with-others, being-as-care, } \\
\text { being-in-language, and being-in-time are already always there no matter what the leader is } \\
\text { dealing with and no matter what his or her way of being and acting in dealing with it. }\end{array}$ \\
\hline The occurring & $\begin{array}{l}\text { Refers to the way in which 1) the leadership challenge the leader is dealing with occurs (shows up) for him or } \\
\text { her; 2) the way in which the possible realizable futures (outcomes of the challenge) occur for her/him; and 3) } \\
\text { the way in which the leader occurs for him/herself in dealing with the particular leadership challenge at hand. }\end{array}$ \\
\hline Context & $\begin{array}{l}\text { Refers to a fundamental set of (often) unchallenged and hidden assumptions inside of which the leader's } \\
\text { dealings show up for him or her. The notion of context involves two distinct but } \\
\text { inseparable elements that arise together: the content (aka, the situation, the circumstances, or the leadership } \\
\text { challenge) and the context that surrounds the content and provides the lens for its } \\
\text { interpretation. }\end{array}$ \\
\hline Absorbed coping & $\begin{array}{l}\text { Refers to the unconscious, skillful dealings of leaders with their routine day to day } \\
\text { activities-driving to work, turning on the computer, using their phone, walking to a meeting-that require } \\
\text { minimal (conscious) intervention of cognitive or emotional states. It is experienced as a harmonious flow of } \\
\text { ways of being and acting in response to whatever situation the leader is } \\
\text { dealing with that does not require any deliberation or planning in advance and does not occupy attention while } \\
\text { occurring. }\end{array}$ \\
\hline Breakdown & $\begin{array}{l}\text { Refer to the result of a foiled intention resulting in a disruption in the leader's absorbed coping. The leader is } \\
\text { forced into deliberation and reflective assessment. In deliberation one stops and } \\
\text { considers what is going on and plans what to do, all in a context of involved activity. Breakdowns create } \\
\text { openings for action. }\end{array}$ \\
\hline Thrownness & $\begin{array}{l}\text { Refers to the leader's inevitable submission to existence itself, in which they find themselves } \\
\text { continuously "thrown” into situations they do not choose and that often seem to be indifferent to their } \\
\text { concerns. In dealing with their "thrown situatedness", the leader is always being some way. }\end{array}$ \\
\hline Intentionality & $\begin{array}{l}\text { The central structure of any experience is its being intentionally directed toward something, e.g., a leadership } \\
\text { challenge. In short, intentionality is aboutness. Intentional action is the result of } \\
\text { activated neural circuits in the brain and, more practical, the conscious experience that "I" am the source of the } \\
\text { action. The intentionality of an action refers to it being deliberate, thoughtful, and goal-oriented. }\end{array}$ \\
\hline Clearing-for-action & $\begin{array}{l}\text { The Heideggerian term "clearing" has a double meaning. It refers to both a material space and to a } \\
\text { metaphorical space of conscious intelligibility in which human beings can "be". In this latter sense, it is the site } \\
\text { where the layers of the leader's hidden and limiting beliefs and assumptions are peeled back. This disclosure of } \\
\text { the authentic self is a "clearing-away" process that opens up a clearing-for-action in which the leader is free to } \\
\text { be and free to act, rather than being constrained by common notions about what it is to be a leader and what it } \\
\text { is to exercise leadership effectively. }\end{array}$ \\
\hline
\end{tabular}

of the "reflection-in-action" aspect of mastery. The actions of reflective practitioners [masters], notes Schön, are characterized by knowledge-in-action and reflection-in-action. Knowing-in-action and reflecting-in-action are here both related to "thinking what one is doing" in the sense of "testing one's way forward."In essence, the leader "becomes a researcher" in the practice context; he does not separate thinking from doing. Knowing-in-action and reflection-in-action are most fundamentally a dialogue with a situation, in which the situation can "talk back". In responding to the back-talk, the leader "reflects-in-action".

All practitioners, knowingly or not, attempt to embed their skills in a pattern language that becomes part of their absorbed coping. Pattern languages help us capture understanding and effectiveness within a particular field of human endeavor, through a set of interconnected terms arising from the as-lived, first-person experience. Experimentation is not eliminated but the scope of effective behaviors is narrowed. "The phenomenology of practice," says Van Manen (Van Manen, 2007), "involves a different way of knowing the world. Whereas theory 'thinks' the world, practice 'grasps' the world-it grasps the world pathically... with 'suffering and also passion."”

Most leadership development programs today teach leadership from a theoretical third-person point of view 
by explaining the properties (traits, attributes, skills) of leaders and leadership. The defect in this approach is that we do not lead using a theoretical, hypothetical approach. Rather, we lead moment-to-moment, situation-to-situation, as a function of the way we experience leadership as-lived, that is, from a first-person point of view. As a result of this inconsistency, we continue to fall short in developing leaders who can tackle the problems that besiege the $21^{\text {st }}$ century.

Greenfield (Greenfield, 2013) used the Google Books Ngram Viewer to search 1.5 million English-language books for relative frequencies of words that could serve as markers of cultural values between the years 1800 to 2000. In her study, she noted that materialistic, individualistic words like "get", "choose”, and "individual" were used more frequently as the years went on, while other centric words like "obliged", "give", and "obedience" decreased in use over time. In other words, obligation, duty, social belongingness, and giving to other peoplepractices which are arguably adaptive in rural settings declined in importance, while self-centeredness and obtaining things for oneself-behaviors that are arguably more adaptive in urban environments increased in importance. These findings underscore the need to rethink our current leadership paradigm and the way in which we currently develop leaders.

"The greatest danger in times of turbulence," writes Peter Drucker, "is not the turbulence; it is to act with yesterday's logic" (Drucker, 1980). Yesterday's logic says that leadership is about a person in charge who wields clout, has answers, and allocates resources. Yesterday's logic says that leadership is about knowing (expertise), having (power, resources) and doing (and competing). We tend to associate having and knowing with being. The more I have and I know, the more I am. In the extreme, the more I have and know, the more important I am. This leadership paradigm must be inverted. "[We] must reinterpret, newly interpret, invent meaning [and] generate new futures and new significances," says Gene Gendlin, "in order to mold the already given troubling meanings of [leadership] situation” (Gendlin, 1967).

Keller and Price (Keller and Price, 2011) point out that “most executives don’t see themselves as "part of the problem." Therefore, deep down, they do not believe that it is they who need to change, even though in principle they agree that leaders must model the desired changes "...In many behavior-related areas, human beings consistently think they are better than they are...." Nonetheless, most of us want to improve our leadership shortcomings but we often don't know how to go about it. Simply "willing” ourselves to change our unproductive ways of being and acting often fails because our moment-to-moment, situation-to-situation ways of being and acting are determined by neural networks. You do not control your way of being-your brain does (Erhard et al., 2013; Souba, 2013). If you could choose your way of being, you would instantly change it whenever you wanted to or thought you should.

We often recognize the complexity of our leadership dilemmas and that technical solutions are insufficient. But we generally fall short in preparing people for what it will take to take these on. Phenomenological reflection gives us access to a broader range of ways of being, thinking, and acting in order to be more effective in dealing with those challenges for which conventional strategies are inadequate. However, Feigenbaum (Feigenbaum, 1983) reminds us that "the matters that set experts apart from beginners, are symbolic, inferential, and rooted in experiential knowledge...But [a]n expert's knowledge is often ill-specified or incomplete because the expert himself doesn't always know exactly what it is he knows about his domain.” So, this further complicates our leadership development challenge.

An opportunity for a breakthrough in leadership effectiveness has emerged from the recognition that the relationship between the situation (challenge) the leader is dealing with and his/her response (specific actions) to that challenge has certain definitive characteristics (Erhard et al., 2013; Zaffron, 2010). First, it is dependently co-arising, which means that the leader's actions-the source of the leader's performance-are always a match (are consistent with) with the occurring. Second, its inquiry is phenomenological; it uses the first-person "aslived" perspective to reveal leadership phenomena (e.g., a budget challenge, an obsolete strategic plan, adysfunctional organizational culture) as they occur in our conscious experience and thus the meanings they have in our experience. Finally, these issues are language-based in the sense that we can only make sense of themunderstand them-by way of language; "language alone brings what is, as something that is, into the open for the first time" (Heidegger, 1996). One way or another, the words we use are disclosive because we always "see" the world through the lenses of our language distinctions.

A first-person phenomenological inquiry provides direct access to what it is to be a leader and what it means to exercise good leadership in real time. This "as-lived/lived-through" perspective calls into question the veiled beliefs and assumptions that determine the decisions leaders make and the actions they take. When these con- 
texts become unveiled, it allows for the creation of new contexts that give leaders more space and greater degrees of freedom to lead more effectively. A first-person approach unclutters the leader's ontologic space, which allows them to make changes in their deeply engrained mental models, values and belief systems. This is essential in today's world when a different "you”, a more powerful and effective you, is called for. Von Ward (Von Ward, 2012) summarizes the daunting challenge we must confront, which is likely to require a phenomenological "remedy":

In [our] attempts to develop strategies for serious social change the first step should be identification of the underlying worldviews that are responsible for the problems...The case is very strong that humans are in a self-made crisis based on worldviews that benefit a few and subject the masses to their consequences...Without a constructive fundamental shift in worldviews, the challenges of climate change, over-population, internecine strife, deteriorating physical health, and isolation from other intelligent life cannot be met...We need a new path.

Creating leaders is very different than (and more effective than) lecturing people about leadership and assuming they will become leaders. Because the phenomenological "facts" of lived experience reside in language, creating for oneself what it is to be a leader requires mastery of a certain language of leadership from which leaders can orient their being, thinking, and actions. The predominant conversational domain of leadershipwhich includes terms like strategy, vision, and competitive differentiation-gives us access to leadership as a set of theories and explanations. This paper contends that any new conversational domain would have to provide one access to leader and leadership as a lived experience. The uniqueness of a first-person phenomenological approach lies in its ability to unveil the hidden contexts that shape the ways of being and acting that are the source of the leader's performance. New ways of being and acting then become possible, which, in turn, alters the leader's performance. This shift is critical because our way of being-in-the-world defines the contextualizing perspective from which we encounter and respond to things in the world (Hyde, 1991).

An underlying premise of this article is that what it is to be a leader is inextricably linked to what it is to be human. Hence, the emphasis on defining the existential characteristics of human "being". By virtue of the fact that we are human, these structures are already always there no matter what situation you and I are dealing with and no matter what our way of being and acting in dealing with it. Thus, anyone can lead. This is good news. More than ever, leadership must permeate all levels of society to include those people who have, in the past, viewed their jobs as having nothing to do with leadership.

We have barely scratched the surface in our efforts to create leaders who can bend the curve of humanity's current course. In the mid-twenty-first century, people will hopefully look back on our present practices of developing leaders and characterize them as primitive. We cannot wait that long. We can do better now, much better.

\section{Conclusion}

As the gravity of global challenges continue to escalate, the need for more effective leadership has become more urgent than ever. Given that the conventional third-person approach to developing leaders has been nominally effective, this paper proposes adopting a first-person phenomenological methodology, which provides direct access to what it is to be a leader and what it is to exercise competent leadership. This approach does not deny the importance of what leaders know and do, but emphasizes more fundamentally the structures of human "being" that make it possible to be a leader in the first place. This "flipping" of the prevailing leadership paradigm presumes that 1) individual transformation must parallel organizational transformation and 2) if you're not being a leader, it is next to impossible to act like a leader. The ensuing improvement in performance is less the result of having learned some new concept or theory and more a function of having altered the context through which one's challenges are understood.

\section{Acknowledgements}

The author thanks Corey Anton, Kathi Becker, Daniel Dahlstrom, and Werner Erhard for their helpful conversations and insights.

\section{References}

Agosta, L. (2010). Empathy in the Context of Philosophy. New York: Palgrave Macmillan. 
http://dx.doi.org/10.1057/9780230275249

Aho, K. (2009). Heidegger's Neglect of the Body. Albany, NY: State University of New York Press.

Anton, C. (1999). Beyond the Constitutive-Representational Dichotomy: The Phenomenological Notion of Intentionality. Communication Theory, 9, 26-57. http://dx.doi.org/10.1111/j.1468-2885.1999.tb00161.x

Anton, C. (2014). Diachronic Phenomenology: A Methodological Thread within Media Ecology. Explorations in Media Ecology, 13, 9-36. http://dx.doi.org/10.1386/eme.13.1.9_1

Bineham, J. (1995). The Hermeneutic Medium. Philosophy and Rhetoric, 28, 1-16.

Blattner, W. (2005). Temporality. In H. Dreyfus, \& M. Wrathall (Eds.), A Companion to Heidegger (pp. 311-324). Malden, MA: Blackwell Publishing. http://dx.doi.org/10.1002/9780470996492.ch19

Blattner, W. (2006). Heidegger's Being and Time: A Reader's Guide. London: Continuum Books.

Boje, D., Oswick, C., \& Ford, J. (2004). Language and Organization: The Doing of Discourse. Academy of Management Review, 29, 571-577.

Borrie, W. (1995). Letting It Be: Heidegger, Leisure and Wilderness. 1995 National Recreation and Park Association Leisure Research Symposium. http://www.cfc.umt.edu/personnel/borrie/papers/heid/

Burch, R. (1990). Phenomenology, Lived Experience: Taking a Measure of the Topic. Phenomenology + Pedagogy, 8, 130-160.

Burns, J. M. (1978). Leadership. New York: Harper and Row.

Calarco, M., \& Atterton, P. (2003). The Continental Ethics Reader. New York: Routledge.

Carruthers, P. (1996). Language, Thought and Consciousness: An Essay in Philosophical Psychology. Cambridge: Cambridge University Press. http://dx.doi.org/10.1017/CBO9780511583360

Costall, A. (1995). Socializing Affordances. Theory \& Psychology, 5, 467-481. http://dx.doi.org/10.1177/0959354395054001

Critchley, S. (2009a). Being and Time, Part 3: Being-in-the-World. http://www.theguardian.com/commentisfree/belief/2009/jun/22/heidegger-religion-philosophy

Critchley, S. (2009b). Being and Time, Part 4: Thrown into this World. http://www.theguardian.com/commentisfree/belief/2009/jun/29/religion-philosophy

Dahlstrom, D. (2013). Heidegger’s Ontological Analysis of Language. In J. Powell (Ed.), Heidegger and Language (pp. 1331). Bloomington, IN: Indiana University Press.

Dahlstrom, D. (2014). Existential Socialization. In H. Pedersen et al. (Eds.), Horizons of Authenticity in Phenomenology, Existentialism, and Moral Psychology (pp. 329-346). New York: Springer.

Deming, W. (1986). Out of the Crisis. Cambridge: MIT Press.

Douglas, N., \& Wykowski, T. (2010). From Belief to Knowledge: Achieving and Sustaining an Adaptive Culture in Culture in Organizations. Boca Raton, FL: CRC Press. http://dx.doi.org/10.1201/EBK1439837344

Dreyfus, H. (1991). Being-in-the-World: A Commentary on Heidegger's Beingand Time, Division I. Cambridge: MIT Press.

Dreyfus, H. (1993). Heidegger's Critique of the Husserl/Searle Account of Intentionality. Social Research, 60, 143-170.

Dreyfus, H. (2002). Refocusing the Question: Can There Be Skillful Coping without Propositional Representations or Brain Representations? Phenomenology and the Cognitive Sciences, 1, 413-425. http://dx.doi.org/10.1023/A:1021303723047

Dreyfus, H., \& Dreyfus, S. (1996). The Relationship of Theory and Practice in the Acquisition of Skill. In P. Benner, C. Tanner, \& C. Chesla (Eds.), Expertise in Nursing Practice: Caring, Clinical Judgment, and Ethics (pp. 1-24). New York: Springer.

Dreyfus, H., \& Wrathall, M. (2005). Martin Heidegger: An Introduction to His Thought, Work, and Life. In H. Dreyfus, \& M. Wrathall (Eds.), A Companion to Heidegger (pp. 1-15). Malden, MA: Blackwell Publishing. http://dx.doi.org/10.1002/9780470996492.ch1

Dreyfus, S., \& Dreyfus, H. (1980). A Five-Stage Model of the Mental Activities Involved in Directed Skill Acquisition. http://stinet.dtic.mil/cgi-bin/GetTRDoc?AD=ADA084551\&Location=U2\&doc=GetTRDoc.pdf

Drucker, P. (1980). Managing in Turbulent Times. New York: Harper-Collins.

Erhard, W. (2009). How Language Shapes the World: A New Model Providing Actionable Access to the Source of Performance (PDF File of Powerpoint Slides). Barbados Group Working Paper No. 09-03, John F. Kennedy School of Government, Harvard University. http://ssrn.com/abstract=1483082 http://dx.doi.org/10.2139/ssrn.1483082

Erhard, W., Jensen, M., \& DiMaggio, J. (2013). Living with Mastery: What It Takes (PDF File of PowerPoint Slides). Harvard Business School NOM Unit Working Paper 11-067, Barbados Group Working Paper No. 11-01. http://ssrn.com/abstract=1720884 
Erhard, W., Jensen, M., \& Granger, K. (2011). Creating Leaders: An Ontological/Phenomenological Model. In S. Snook, N. Nohria, \& R. Khurana (Eds.), The Handbook For Teaching Leadership (pp. 245-262). Thousand Oaks, CA: Sage Publications.

Feigenbaum, E. (1983). The Fifth Generation: Artificial Intelligence and Japan's Computer Challenge to the World. Boston, MA: Addison Wesley Publishing.

Flatley, J. (2008). Affective Mapping: Melancholia and the Politics of Modernism. Cambridge, MA: Harvard University Press.

Gadamer, H. G. (2005). Truth and Method. Translated and Edited by J. Weinsheimer, \& D. G. Marshall. New York: Continuum Publishing Group.

Gaines, E. (2003). The Necessary Ambiguity of Communication. Semiotics 2002. Semiotic Society of America. In T. Prewitt, \& J. Deely (Eds.), Media Literacy and Semiotics. New York: Legas Publishing.

Gallagher, S., \& Zahavi, D. (2014). Primal Impression and Enactive Perception. In D. Lloyd, \& V. Arstila (Eds.), Subjective Time: The Philosophy, Psychology, and Neuroscience of Temporality (pp. 83-99). Cambridge, MA: MIT Press.

Gardner, J. (1990). On Leadership. New York: The Free Press.

Gelven, M. (1989). A Commentary on Heidegger's Being and Time. Dekalb, IL: Northern Illinois University Press.

Gendlin, E. (1967). An Analysis of What Is a Thing? In M. Heidegger (Ed.), What Is a Thing? (W. Barton, \& V. Deutsch, Trans., pp. 247-296). Chicago, IL: Henry Regnery. http://www.focusing.org/gendlin/docs/gol_2041.html

Geniusas, S. (2012). The Origins of the Horizon in Husserl's Phenomenology. New York: Springer. http://dx.doi.org/10.1007/978-94-007-4644-2

Gibbs, P. (2011). The Concept of Profound Boredom: Learning from Moments of Vision. Studies in Philosophy and Education, 30, 601-613. http://dx.doi.org/10.1007/s11217-011-9256-5

Greenfield, P. (2013). The Changing Psychology of Culture from 1800 through 2000. Psychological Science, 24, $1722-1731$. http://dx.doi.org/10.1177/0956797613479387

Guignon, C. (1993). Authenticity, Moral Values, and Psychotherapy. In C. Guignon (Ed.), The Cambridge Companion to Heidegger (pp. 215-239). New York: Cambridge University Press. http://dx.doi.org/10.1017/CCOL0521385709.009

Gurwitsch, A. (1979). Human Encounters in the Social World. Pittsburgh, PA: Duquesne University Press.

Heidegger, M. (1962). Being and Time. Trans. by J. Macquarrie, \& E. Robinson. London: SCM Press.

Heidegger, M. (1966). Discourse on Thinking. Trans. by J. Anderson, \& E. Freund. New York: Harper and Row.

Heidegger, M. (1968). What Is Called Thinking? Trans. by J. Glenn Gray. New York: Harper and Row.

Heidegger, M. (1982). The Basic Problems of Phenomenology. Trans. by A. Hofstadter. Bloomington, IN: IA University Press.

Heidegger, M. (1993a). The Way to Language. In: D. Krell (Ed.), Basic Writings (pp. 393-426). New York: Harper Collins.

Heidegger, M. (1993b). Letter on Humanism. In: D. Krell (Ed.), Basic Writings (pp. 213-266). New York: Harper Collins.

Heidegger, M. (1996). Being and Time. Trans. by J. Stambaugh. Albany, NY: State University of New York Press.

Heidegger, M. (2002). The Origin of the Work of Art. In: Off the Beaten Track (Trans. by J. Young, \& K. Haynes, pp. 1-56). Cambridge: Cambridge University Press.

Heifetz, R., \& Laurie, D. (2001). The Work of Leadership. Harvard Business Review, 79, 131-141.

Hoefer, C. (2010). Causal Determinism. The Stanford Encyclopedia of Philosophy (Spring 2010), EN Zalta (Ed.). http://plato.stanford.edu/archives/spr2010/entries/determinism-causal/

Hyde, M. (1983). Rhetorically Man Dwells: On the Making-Known Function of Discourse. Communication, 7, $201-220$.

Hyde, R. B. (1991). Saying the Clearing: A Heideggerian Analysis of the Ontological Rhetoric of Werner Erhard. Ph.D. Dissertation, Los Angeles, CA: University of Southern California.

Hyde, R. B. (1994). Listening Authentically: A Heideggerian Perspective on Interpersonal Communication. In K. Carter, \& M. Presnell (Eds.), Interpretive Approaches to Interpersonal Communication (pp. 179-197). Albany, NY: SUNY Press.

Ingthorsson, R. (2013). The Natural vs. the Human Sciences: Myth, Methodology and Ontology. Discusiones Filosoficas, 14, 25-34.

Iran-Nejad, A., \& Houser, R. (2013). From Second/Third-Person Education Monodisciplines to First-Person Educational Science: An Integrating Disciplines Perspective. Academia Journal of Educational Research, 1, 8-18.

Jacquin, C. S. A. I. N. T. (2013). How to Live More Fully in the Spirit. Bloomington, IN: Balboa Press.

Joy, L. (2002). Individual and Societal Transformation: The Connection.

http://www.quakerinstitute.org/?page_id=5 
Kekes, J. (1980). Nature of Philosophy. Totowa, NJ: Rowman and Littlefield.

Keller, S., \& Price, C. (2011). Beyond Performance: How Great Organizations Build Ultimate Competitive Advantage. New York: Wiley.

Kockelmans, J. (1987). Husserl’s Original View on Phenomenological Psychology. In J. Kockelmans (Ed.), Phenomenological Psychology: The Dutch School (pp. 3-29). Dordrecht: Martinus Nijhoff. http://dx.doi.org/10.1007/978-94-009-3589-1_1

Korab-Karpowicz, W. (2009). http://www.iep.utm.edu/heidegge/

Korsgaard, C. (1996). The Sources of Normativity. New York: Cambridge University Press. http://dx.doi.org/10.1017/CBO9780511554476

Krausz, M. (2002). Is There a Single Right Interpretation? University Park, PA: Pennsylvania State University Press.

Laing, R. D. (1967). The Politics of Experience. London: Routledge \& Kegan Paul.

Lebeau, L., \& Maclean, D. (2006). Awakening the Fire within: Relationship, Leadership \& Self-Esteem. Bloomington, IN: Trafford Publishing.

Lester, G. (2000). Why Bad Beliefs Don’t Die. Skeptical Inquirer, 24. http://www.csicop.org/si/show/why_bad_beliefs_dont_die

Levine, L. (1988). Bird: The Making of an American Sports Legend. New York: McGraw Hill.

Lung, H. (2011). Ultimate Mind Control. New York: Citadel Publishers.

Markic, O. (2012). First- and Third-Person Approaches: The Problem of Integration. Interdisciplinary Description of Complex Systems, 10, 213-222. http://dx.doi.org/10.7906/indecs.10.3.1

McKenna, W. (1982). Husserl's Introductions to Phenomenology: Interpretation and Critique. The Hague: Martinus Nijhoff.

Moore, C. F. (1909). Moore's History of the United Sates: United and Otherwise. New York: Neale Publishing.

Moran, D. (2000). Introduction to Phenomenology. New York: Routledge.

Moustakas, C. (1994). Phenomenological Research Methods. Thousand Oaks, CA: Sage.

Mulhall, S. (1996). Heidegger and Being and Time. London: Routledge.

Nadal, P. (2010). Thinking Being Human: Notes on Heidegger’s Letter on Humanism. http://belate.wordpress.com/2010/11/18/heidegger-letter-on-humanism/

Okrent, M. (1999). Heidegger and Korsgaard on Human Reflection. Philosophical Topics, 27, 47-76. http://dx.doi.org/10.5840/philtopics19992724

Palmer, R. E. (1969). Hermeneutics: Interpretation Theory in Schleiermacher, Dilthey, Heidegger, and Gadamer. Evanston, IL: Northwestern University Press.

Pangaro, P. (1996). Cybernetics and Conversation. http://www.pangaro.com/published/cyb-and-con.html

Pangaro, P. (2002). Notes on the Role of Leadership and Language in Regenerating Organizations. http://pangaro.com/leadership-language-regenerating-organizations.html

Pascale, R., Milleman, M., \& Gioja, L. (2000). Surfing the Edge of Chaos. New York: Three Rivers Press.

Pinker, S. (2000). Words and Rules: The Ingredients of Language. Quezon City: Phoenix Publishing.

Polt, R. (2005). Heidegger's Being and Time: Critical Essays. Lanham, MD: Rowman and Littlefield.

Rhees, R. (1984). Recollections of Wittgenstein. Oxford: Blackwell.

Rorty, R. (1986). The Contingency of Language. London Review of Books, 8, 3-6.

Sallis, J. (1995). Delimitations: Phenomenology and the End of Metaphysics. Bloomington, IN: Indiana University Press.

Sartre, J. P. (1946). Existentialism Is a Humanism. Cleveland, OH: World Publishing Company.

Schatzki, T. (2005). Early Heidegger on Sociality. In H. Dreyfus, \& M. Wrathall (Eds.), A Companion to Heidegger (pp. 233-247). Malden, MA: Blackwell Publishing. http://dx.doi.org/10.1002/9780470996492.ch14

Schön, D. (1983). The Reflective Practitioner. How Professionals Think in Action. New York: Basic Books.

Schön, D. (1987). Educating the Reflective Practitioner: Toward a New Design for Teaching and Learning in the Professions. San Francisco, CA: Jossey-Bass.

Smith, D. (2013). Phenomenology. The Stanford Encyclopedia of Philosophy (Winter Edition). E. N. Zalta (Ed.). http://plato.stanford.edu/archives/win2013/entries/phenomenology/.

Smythe, E., \& Norton, A. (2007). Thinking as Leadership/Leadership as Thinking. Leadership, 3, 65-90. http://dx.doi.org/10.1177/1742715007073067 
Soccio, T. (2007). Archetypes of Wisdom: An Introduction to Philosophy. Belmont, CA: Thomson Wadsworth.

Souba, W. (2006). The Inward Journey of Leadership. Journal of Surgical Research, 131, 159-167. http://dx.doi.org/10.1016/j.jss.2006.01.022

Souba, W. (2010). The Language of Leadership. Academic Medicine, 85, 1609-1618. http://dx.doi.org/10.1097/ACM.0b013e3181ee0045

Souba, W. (2011). Perspective: A New Model of Leadership Performance in Health Care. Academic Medicine, 86, 12411252. http://dx.doi.org/10.1097/ACM.0b013e31822c0385

Souba, W. (2013). The Science of Leading Yourself: A Missing Piece in the Healthcare Reform Puzzle. Open Journal of Leadership, 2, 45-55. http://dx.doi.org/10.4236/ojl.2013.23006

Souba, W. (2014). Rethinking Leadership Development. The Pharos, 77, 3-6.

Steiner, C. (2002). The Technicity Paradigm and Scientism in Qualitative Research. The Qualitative Report, 7. http://www.nova.edu/ssss/QR/QR7-2/steiner.html Accessed 3/19/2014

Steiner, G. (1978). Heidegger. Sussex: Harvester Press Limited.

Sutton, J., McIlwain, D., Christensen, W., \& Geeves, A. (2011). Applying Intelligence to the Reflexes: Embodied Skills and Habits between Dreyfus and Descartes. Journal of the British Society for Phenomenology, 42, 79-103. http://dx.doi.org/10.1080/00071773.2011.11006732

Tieszen, R. (2013). Analytic and Continental Philosophy, Science, and Global Philosophy. In B. Mou, \& R. Tieszen (Eds.), Constructive Engagement of Analytic and Continental Approaches in Philosophy (pp. 103-124). Leiden: Koninklijke Brill. http://dx.doi.org/10.1163/9789004248861_009

Twain, M. (1888). Letter to George Bainton. http://www.twainquotes.com/Lightning.html

Van Gulick, R. (2014). Consciousness. In E. N. Zalta (Ed.), The Stanford Encyclopedia of Philosophy. Berlin: Spring. http://plato.stanford.edu/archives/spr2014/entries/consciousness/.

Van Manen, M. (2007). Phenomenology of Practice. Phenomenology \& Practice, 1, 11-30.

Van Manen, M. (2011). Language Itself Is a Source of Meaning. Phenomenology Online. http://www.phenomenologyonline.com/inquiry/sources-of-meaning/language-sources/

Van Manen, M. (2014). Phenomenology of Practice: Meaning-Giving Methods in Phenomenological Research and Writing. Walnut Creek, CA: Left Coast Press.

Varela, F., \& Shear, J. (1999). First-Person Methodologies: What, Why, How? Journal Consciousness Studies, 6, 1-14.

Von Ward, P. (2012). Worldviews and Evolution of Human Consciousness. Spanda Journal, 3. http://vonward.com/images/SpandaWVEssay_VonWard.pdf

Webber, J. (2002). Doing without Representation: Coping with Dreyfus. Philosophical Explorations: An International Journal for the Philosophy of Mind and Action, 5, 82-88. http://dx.doi.org/10.1080/10002002018538723

Wheeler, M. (2013). Martin Heidegger. In E. N. Zalta (Ed.), The Stanford Encyclopedia of Philosophy (Spring 2013 Edition). http://plato.stanford.edu/archives/spr2013/entries/heidegger/

Wiener, N. (1988). The Human Use of Human Beings: Cybernetics and Society. Boston, MA: Da Capo Press.

Wilde, O. (1964). De Profundis. New York: Vintage Books.

Zaffron, S., \& Logan, D. (2009). The Three Laws of Performance. San Francisco, CA: Jossey-Bass. 
Scientific Research Publishing (SCIRP) is one of the largest Open Access journal publishers. It is currently publishing more than 200 open access, online, peer-reviewed journals covering a wide range of academic disciplines. SCIRP serves the worldwide academic communities and contributes to the progress and application of science with its publication.

Other selected journals from SCIRP are listed as below. Submit your manuscript to us via either submit@scirp.org or Online Submission Portal.
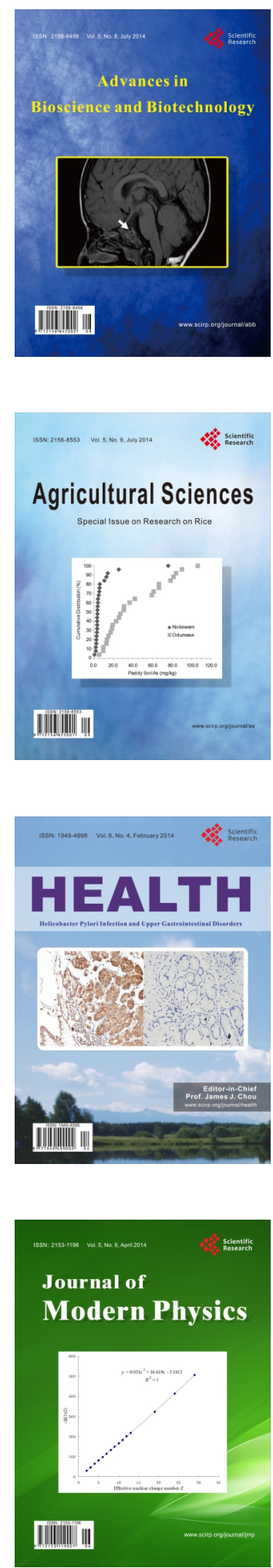
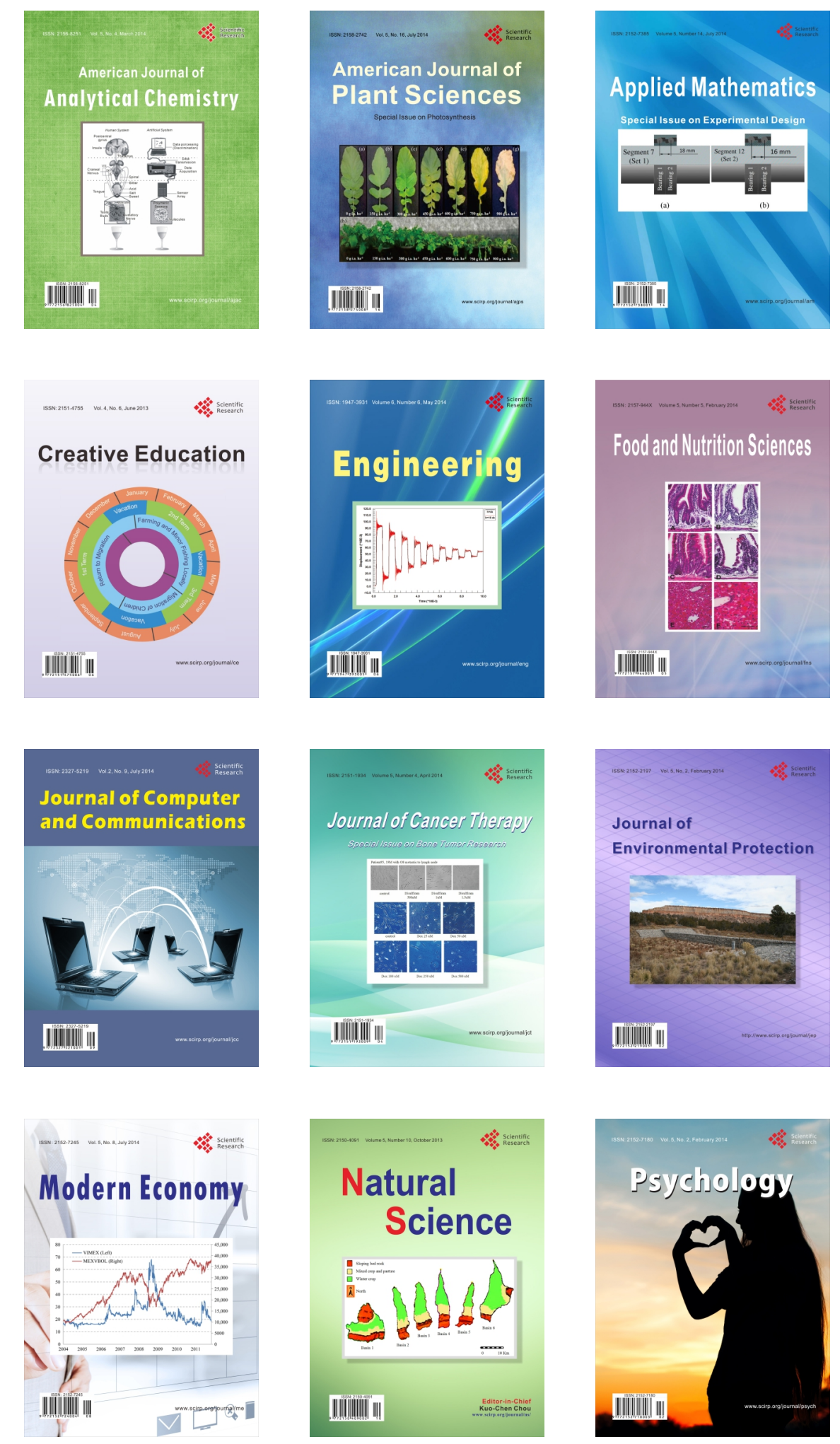